FHWA/IN/JTRP-2000/15

Final Report

PROVIDING REAL-TIME TRAFFIC ADVISORY AND ROUTE GUIDANCE TO MANAGE BORMAN INCIDENTS ON-LINE USING THE HOOSIER HELPER PROGRAM

Srinivas Peeta

Jorge Ramos

Shyam Gedela

November 2000 
Final Report

FHWA/IN/JTRP-2000/15

\title{
Providing Real-Time Traffic Advisory and Route Guidance to Manage Borman Incidents On-line Using the Hoosier Helper Program
}

\author{
by \\ Srinivas Peeta \\ Principal Investigator \\ Associate Professor of Civil Engineering \\ and \\ Jorge L. Ramos \\ and \\ Shyam Gedela \\ Graduate Research Assistants \\ Purdue University \\ School of Civil Engineering \\ Joint Transportation Research Program \\ Project No. C-36-71L \\ File No. 8-9-12 \\ SPR 2208 \\ Prepared in cooperation with the \\ Indiana Department of Transportation and the \\ U.S. Department of Transportation \\ Federal Highway Administration
}

The contents of this report reflect the views of the authors who are responsible for the facts and the accuracy of the data presented herein. The contents do not necessarily reflect the official views or policies of the Indiana Department of Transportation or the Federal Highway Administration at the time of publication. This report does not constitute a standard, specification, or regulation.

Purdue University

West Lafayette, Indiana 47907

November 2000 
TECHNICAL REPORT STANDARD TITLE PAGE

\begin{tabular}{|c|c|c|}
\hline $\begin{array}{l}\text { 1. Report No. } \\
\text { FHWA/IN/JTRP-2000/15 }\end{array}$ & 2. Government Accession No. & 3. Recipient's Catalog No. \\
\hline \multirow{2}{*}{\multicolumn{2}{|c|}{$\begin{array}{l}\text { 4. Title and Subtitle } \\
\text { Providing Real-Time Traffic Advisory and Route Guidance to Manage Borman } \\
\text { Incidents On-Line Using the Hoosier Helper Program }\end{array}$}} & $\begin{array}{l}\text { 5. } \quad \text { Report Date } \\
\text { November } 2000\end{array}$ \\
\hline & & 6. Performing Organization Code \\
\hline \multicolumn{2}{|c|}{$\begin{array}{l}\text { 7. Author(s) } \\
\text { Srinivas Peeta, Jorge Ramos, and Shyam Gedela }\end{array}$} & $\begin{array}{l}\text { 8. Performing Organization Report No. } \\
\text { FHWA/IN/JTRP-2000/15 }\end{array}$ \\
\hline \multirow{2}{*}{\multicolumn{2}{|c|}{$\begin{array}{l}\text { 9. Performing Organization Name and Address } \\
\text { Joint Transportation Research Program } \\
\text { 1284 Civil Engineering Building } \\
\text { Purdue University } \\
\text { West Lafayette, Indiana } 47907-1284\end{array}$}} & 10. Work Unit No. \\
\hline & & $\begin{array}{l}\text { 11. Contract or Grant No. } \\
\text { SPR-2208 }\end{array}$ \\
\hline \multirow{2}{*}{\multicolumn{2}{|c|}{$\begin{array}{l}\text { 12. Sponsoring Agency Name and Address } \\
\text { Indiana Department of Transportation } \\
\text { State Office Building } \\
100 \text { North Senate Avenue } \\
\text { Indianapolis. IN } 46204\end{array}$}} & $\begin{array}{l}\text { 13. Type of Report and Period Covered } \\
\text { Final Report }\end{array}$ \\
\hline & & 14. Sponsoring Agency Code \\
\hline
\end{tabular}

\section{Supplementary Notes}

Prepared in cooperation with the Indiana Department of Transportation and Federal Highway Administration.

\section{Abstract}

This study addresses the issue of whether the message content of variable message signs (VMS) can be used as a control variable to favorably influence traffic conditions in real-time. The focus is on the level of detail of information displayed on the VMS, and not human factor issues. It implies an understanding of driver sensitivity to information content. Also, for real-time implementation, the displayed information should be consistent, timely, and reliable. A framework is developed for optimizing system performance under incidents using the VMS message content as the primary control parameter. It consists of: (i) an efficient control strategy to enhance system performance using the VMS and information on current traffic conditions received from on-line sensors; (ii) a driver response model to supplied information that addresses the effect of the message content on drivers' en-route switching decisions; and (iii) an incident clearance time prediction model which predicts the expected delay due to an incident.

\section{Key Words}

variable message signs, real-time incident management, advanced traffic management systems, simulation-based optimization, consistent route diversion models, internet-based driver survey, incident clearance time prediction model.

\section{Distribution Statement}

No restrictions. This document is available to the public through the National Technical Information Service, Springfield, VA 22161

\begin{tabular}{|c|c|c|c|}
\hline $\begin{array}{c}\text { 19. Security Classif. (of this report) } \\
\text { Unclassified }\end{array}$ & $\begin{array}{c}\text { 20. Security Classif. (of this page) } \\
\text { Unclassified }\end{array}$ & $\begin{array}{c}\text { 21. No. of Pages } \\
111\end{array}$ & 22. Price \\
\hline
\end{tabular}




\section{TECHNICAL Summary}

INDOT Research

Technology Transfer and Project Implementation Information

TRB Subject Code: 54 Operations and Traffic Control

November 2000

Publication No. FHWA/IN/JTRP-2000/15, SPR-2208

Final Report

\section{Providing Real-Time Traffic Advisory and Route Guidance to Manage Borman Incidents On-Line Using the Hoosier Helper Program}

\section{Introduction}

INDOT is currently installing Variable Message Signs (VMS) as part of information-based real-time advanced traffic management systems (ATMS) to enable travelers to make more informed pretrip and en-route route choice decisions. The effectiveness of the VMS strategy in enhancing travel conditions, especially under incidents, depends on driver attitudes and response behavior under the messages displayed. This highlights the importance of the content of the VMS messages displayed and the need for coordinated and consistent control strategies by the system controller. The primary focus of this study is to develop a mechanism to determine the VMS messages to be displayed that enhance system performance and are consistent with driver response behavior.

To enable effective VMS-based incident management, a framework for optimizing system performance was

\section{Findings}

This research has the following findings that meet the research objectives.

1. The driver response behavior models can estimate the diversion rates in response to the displayed VMS message. Further, the diversion rates for freight truck drivers can be specifically determined and can be differentiated developed using the VMS message content as the control variable. It consists of simulation-based algorithms to determine the optimal VMS messages to be displayed, driver response behavior models under the displayed VMS messages, and an incident clearance time prediction model to estimate the incident duration. The driver behavior models were classified into freight truck and non-truck categories to differentiate between the response attitudes of freight truck drivers and other travelers vis-a-vis en-route route diversion.

The Borman Expressway corridor in northwest Indiana was used as a case study to develop the driver response behavior models and the incident clearance time prediction model. Simulation-based off-line testing and evaluation of the effectiveness of the VMS message strategies were performed. from the diversion rates for other travelers.

2. The incident clearance time prediction model that estimates the incident duration as part of the incident management framework uses data on ambient traffic conditions, incident severity, and weather conditions. 
3. The driver response models for the Borman Expressway were developed using stated preference on-site, mailback, and Internet-based surveys. The Internet-based survey is generic and provides a low-cost readily-available mechanism to INDOT to conduct such surveys at other locations as warranted.

\section{Implementation}

The proposed VMS-based framework can be implemented on the Borman Expressway corridor for on-line

\section{Contact}

For more information:

\section{Prof. Srinivas Peeta}

Principal Investigator

School of Civil Engineering

Purdue University

West Lafayette, IN 47907

Phone: (765) 494-2209

Fax: (765) 496-1105
4. The simulation-based optimal VMS message algorithms determine the messages to be displayed that are consistent with driver attitudes in the region. testing and real-time operation after the ATMS installation by INDOT is completed.

\section{Indiana Department of Transportation}

Division of Research

1205 Montgomery Street

P.O. Box 2279

West Lafayette, IN 47906

Phone: (765) 463-1521

Fax: (765) 497-1665

Purdue University

Joint Transportation Research Program

School of Civil Engineering

West Lafayette, IN 47907-1284

Phone: (765) 494-9310

Fax: (765) 496-1105 


\section{ACKNOWLEDGEMENTS}

The authors acknowledge the assistance of the members of the study advisory committee: Mike Bowman, Dan Buck, Shou Li, Kirk Mangold, and Dan Shamo from the Indiana Department of Transportation, as well as Dennis Lee from the Federal Highway Administration. The authors would also like to thank Troy Boyd of the Indiana Department of Transportation for his valuable assistance in obtaining Borman incident data and for providing information and feedback on the Borman advanced traffic management system. The authors further acknowledge Wey-Jen Lee and Jeong Whon Yu for their assistance in data collection as part of the on-site driver survey, and Raghubhushan Pasupathy for interactions on discrete choice modeling of the survey data.

This project was funded by the Joint Transportation Research Program of Purdue University in cooperation with the Indiana Department of Transportation and the Federal Highway Administration. We appreciate their support and assistance. 
TABLE OF CONTENTS

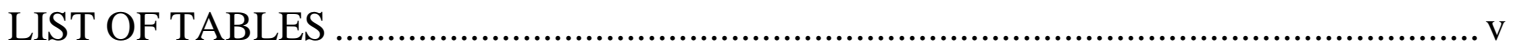

LIST OF FIGURES ...............................................................................................

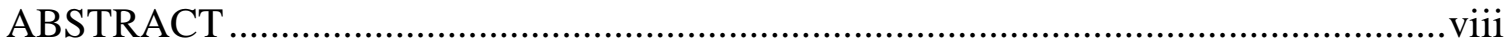

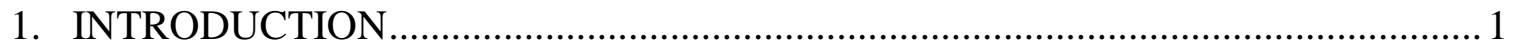

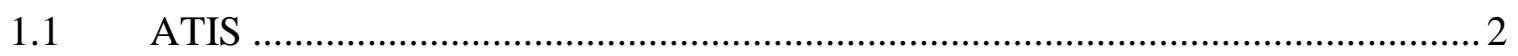

1.2 Problem Statement.................................................................................... 3

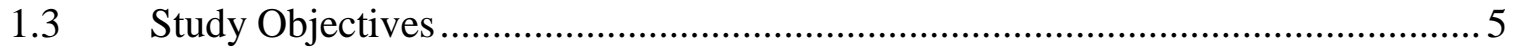

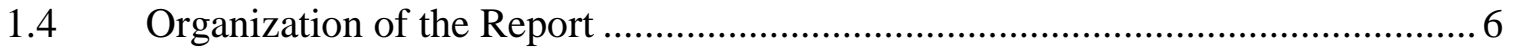

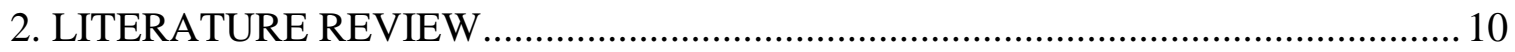

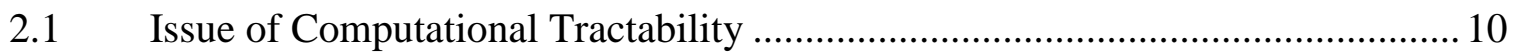

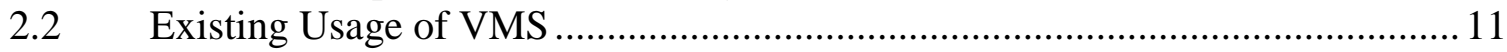

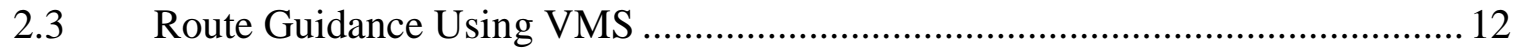

2.4 Role of Simulation in Evaluating Effectiveness of VMS ................................ 14

3. INCIDENT CLEARANCE TIME PREDICTION MODELS .................................. 15

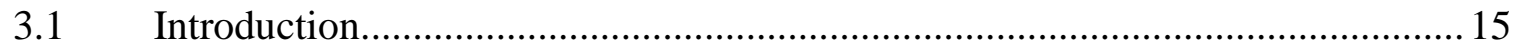

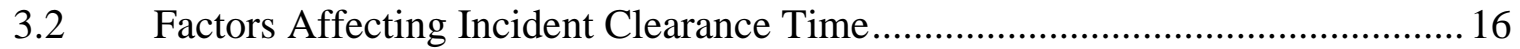

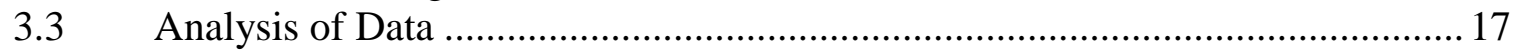

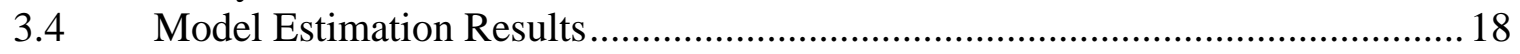



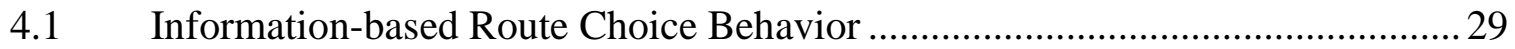

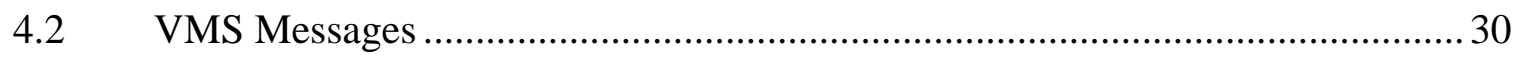

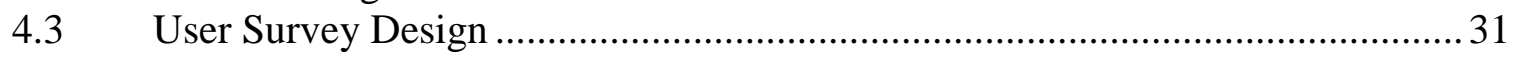

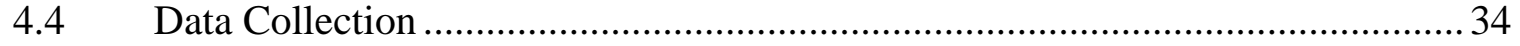

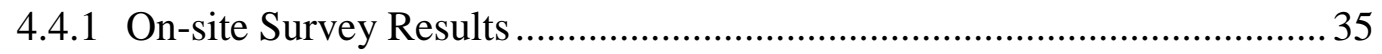

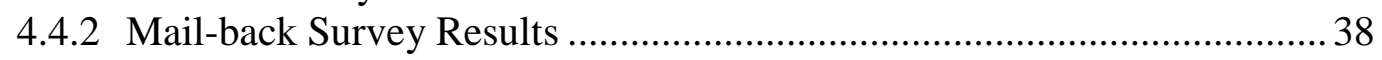


4.4.3 Internet-based Survey Results ........................................................... 40

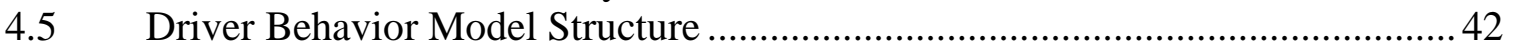



4.6.1 Estimation Using the On-site Survey Data .......................................... 44

4.6.2 Estimation Using the Mail-back Survey Data......................................... 49

4.6.3 Estimation Using the Internet-based Survey Data..................................50

4.6.4 Combined Data Estimation ................................................................ 51

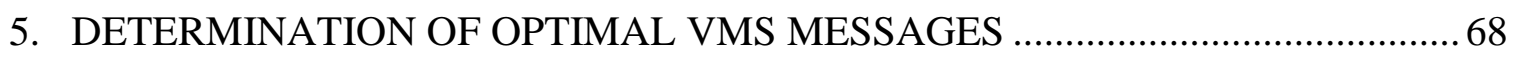

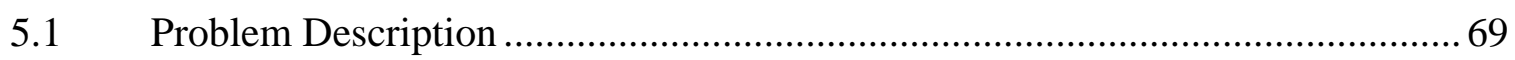

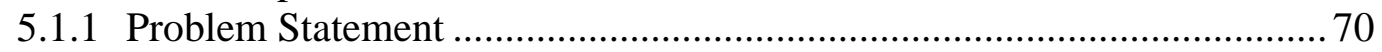





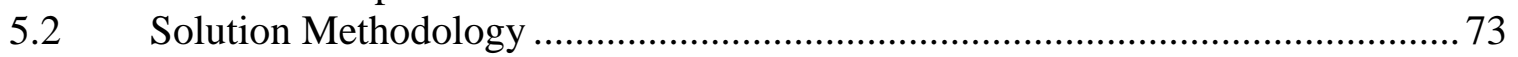

5.2.1 VMS-Based Optimal Diversion Rates Heuristic ................................... 73

5.2.2 The Activation Algorithm................................................................ 74

5.2.3 The Message Display Algorithm (MDA) …....................................... 75

5.2.4 The Update Frequency Algorithm .................................................. 77

$5.3 \quad$ VMS Control Heuristic Implementation ................................................ 78

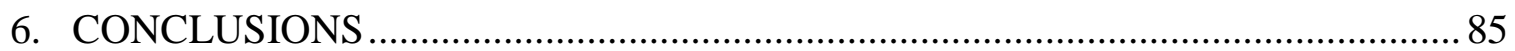



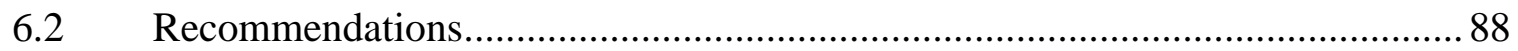

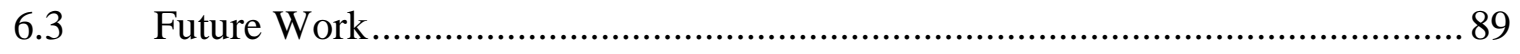

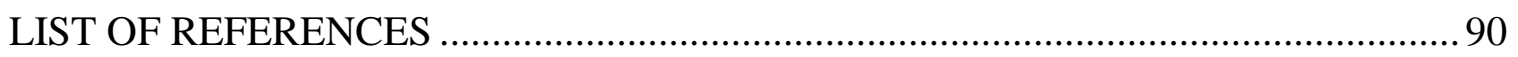

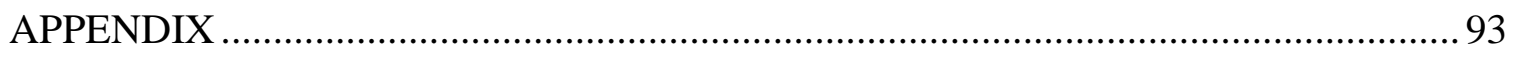




\section{LIST OF TABLES}

Table

3.1 Clearance Time of Hoosier Helper Assisted Incidents (Jul. 1996 - Oct. 1998) ......... 26

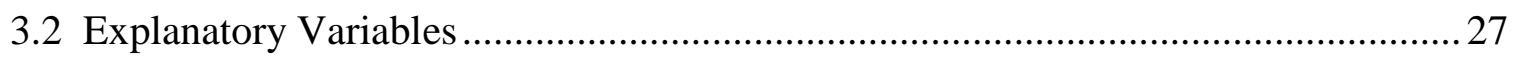

3.3 Models for Prediction of Incident Clearance Time.............................................28



4.2 Socioeconomic Characteristics of the On-site Survey Sample ................................54

4.3 Diversion Characteristics of the On-site Survey Sample ....................................... 55

4.4 Effect of VMS Message Content (On-Site Survey Sample) ....................................56

4.5 Socioeconomic Characteristics of the Mail-back Survey Sample ...........................57

4.6 Diversion Characteristics of the Mail-back Survey Sample ..................................58

4.7 Effect of VMS Message Content (Mail-back Survey Sample) ...............................59

4.8 Socioeconomic Characteristics of the Internet-based Survey Sample ......................60

4.9 Diversion Characteristics of the Internet-based Survey Sample ............................. 61

4.10 Effect of VMS Message Content (Internet-based Survey Sample)........................ 62

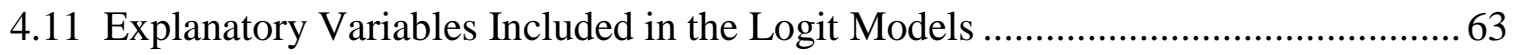

4.12 Logit Models for Driver Response Under VMS Using the On-site Survey Data .... 64

4.13 Logit Model for Driver Response Under VMS Using the Mail-back



4.14 Logit Model for Driver Response Under VMS Using the Internet-based Survey Data 
4.15 Logit Model for Driver Response Under VMS Using the Combined

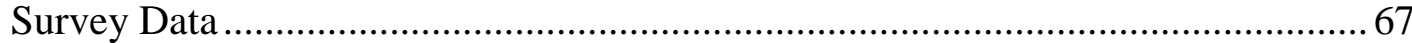




\section{LIST OF FIGURES}

Figure

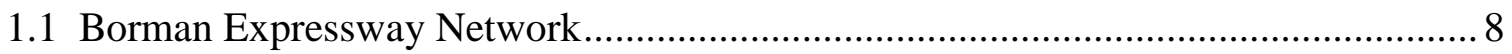

1.2 On-line Route Advisory and Guidance Framework......................................... 9

3.1 Components of Incident Duration ............................................................ 22

3.2 Distribution of Hoosier Helper Assisted Incidents by Type and Lateral Location .... 23

3.3 Plot of Predicted Values Versus Residuals from Incident Clearance Time Prediction Model of Crash Incidents......................................................................... 24

3.4 Plot of Predicted Values Versus Residuals from Incident Clearance Time Prediction

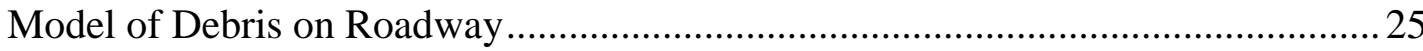

4.1 Driver Response Mechanism Under Information Provision .................................. 52

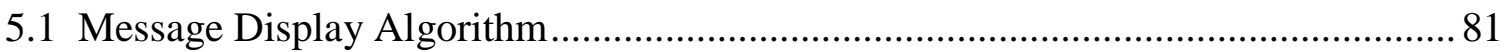

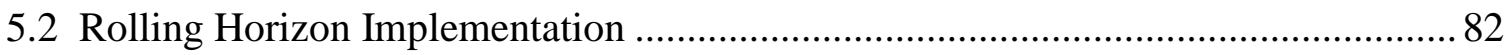

5.3 The Rolling Horizon Implementation of the VMS Control Heuristic in the Stage that

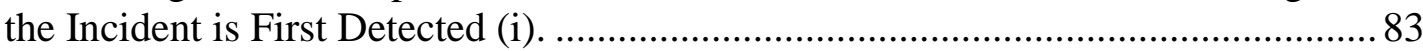

5.4 The Rolling Horizon Implementation of the VMS Control Heuristic in Stages Following the Detection of the Incident 


\section{INTRODUCTION}

Traffic congestion in most urban areas around the world is a daily phenomenon. Congestion can be viewed as the outcome of the interaction between travel demand and capacity supply. When demand for road capacity becomes larger than supply, congestion arises. The effects of congestion, such as excessive delays, increased fuel consumption, and incidents, can be translated into significant economic and social costs. Metropolitan areas in the United States are experiencing unprecedented challenges to mobility. In the past decade, traffic volumes in urban areas have grown by $30 \%$. A recent study has shown that in the next 10 years, the number of vehicles on U.S. roads and highways will increase by $50 \%$ [1]. American people spend 2 billion hours queued in traffic every year, which translates to over 48 billion dollars in lost productivity. State and local governments are struggling with the demands this places on the infrastructure system. As congestion continues to increase in most areas, the conventional approach of building more roads is not always a viable solution primarily for two reasons. First, the lack of space to expand or build new highways renders many alternatives obsolete. Second, building new highways, in many cases, compounds congestion problems by inducing unforeseen demands for travel by auto. 
The U.S. and many countries around the world are applying advanced technologies as tools to manage and operate existing transportation systems in an efficient manner, a paradigm referred to as Intelligent Transportation Systems (ITS). ITS combines the power of communications with a variety of information technologies to better manage and improve the operation of existing transportation systems. ITS can be characterized as a combination of several key elements: Advanced Traffic Management Systems (ATMS), Advanced Traveler Information Systems (ATIS), Advanced Vehicle Control Systems (AVCS), Advanced Rural Transportation Systems (ARTS), Advanced Public Transportation Systems (APTS), and Commercial Vehicle Operations (CVO). In general, the benefits of ITS include: reduced traffic congestion, enhanced public safety, improved access to travel information, and reduced adverse environmental impacts.

\section{$1.1 \underline{\text { ATIS }}$}

Advanced Traveler Information Systems (ATIS) represent one of the strategies employed in recent years to alleviate traffic congestion. ATIS aim to provide motorists travel-related information to enable them to make more informed decisions on congestion avoidance, departure time, route selection, and en-route diversion. They can be classified into pre-trip information services (such as route planning information services through the Internet) and en-route information broadcasting services such as personalized navigation systems, highway advisory radio (HAR), and variable message signs (VMS). In a real-time framework, ATIS can be used by traffic controllers to disseminate information on traffic conditions to trigger optimal routing policies to improve network performance. 


\subsection{Problem Statement}

Incidents or non-recurrent congestion can lead to severe traffic delays as well as deterioration in terms of safety (for example, secondary accidents) and air quality. The Indiana Department of Transportation (INDOT) is currently implementing an ATMS on the Borman Expressway in northern Indiana, a major interstate corridor, to better manage incidents and enhance mobility in the area. The Borman Expressway is a sixteen mile segment of interstates 80 and 94 (I-80/94) and is part of the Gary-Chicago-Milwaukee corridor. It begins at the Indiana/Illinois border and stretches east to the Indiana Toll Road interchange. Figure 1.1 illustrates the Borman Expressway and its associated corridor. The average daily traffic (ADT) on the Borman is approximately 140,000 vehicles, with trucks comprising about $30 \%$ of the traffic on average and peaking at $70 \%$ at night. Traffic volumes are relatively constant from the morning through the early evening, with near or at capacity volume during most of the daylight hours under perfect operational conditions.

Operational problems arise on the Borman Expressway due to non-recurrent congestion, primarily through accidents and stalled vehicles [2]. Over $60 \%$ of the incidents involve passenger vehicles and $20 \%$ involve trucks and semi-trailers. The sizeable percentage of through traffic in the form of cargo-carrying trucks increases the likelihood of their involvement in these accidents. This increases the potential severity of accidents by increasing the average duration of the operation of the expressway under reduced capacity around the bottleneck area. Additional complications arise due to major construction projects currently underway or planned for the next five to ten years. 
The Hoosier Helpers $(\mathrm{HH})$ are freeway service patrols on the Borman Expressway. They have been identified as the system operator in the field and an essential player in the rapid detection, verification, response, and removal of incidents. In order to effectively and rapidly manage incidents, the $\mathrm{HH}$ operators have specially equipped vehicles to operate key elements of the system directly from the vehicle, with capabilities to communicate with the central system in the Traffic Management Center (TMC), perform various system functions, log new incidents, and initiate response actions (including the notification of emergency and law enforcement agencies). While this helps to develop a coordinated effort and reduce the incident response and clearance time, they lack the capabilities to effectively manage traffic during incident clearance and minimize the amount of traffic adversely impacted by an incident.

VMS and HAR are the primary technologies being considered for the Borman Expressway ATMS. VMS are the most visible means of dissemination of traffic information. They are electronic message boards placed in close proximity to roadways. They allow traffic controllers to inform drivers on changing traffic conditions, and are commonly used for parking guidance, control of high occupancy vehicle (HOV) lanes, congestion warnings, safety warnings, and traffic flow diversion. While they have an obvious role under incidents in terms of improving network performance, they have the potential to contribute positively under recurrent congestion and special events as well. Unlike in-vehicle navigation systems (IVNS), which can provide personalized routing information, VMS are constrained to display generic information. This places a higher premium on the message displayed through a VMS in the context of its relative effect on system performance. Currently, the system operator lacks an anticipatory capability of 
determining what type of VMS-based information should be provided to motorists. INDOT is currently developing an expert system to address the following issues for Borman incident management: (i) whether to inform drivers of incidents, (ii) when to advise drivers to switch and to which diversion routes, (iii) when to modify advisories, (iv) when to remove such advisories, and (v) which VMS locations to activate to display information, so at to minimize traffic delays and the number of drivers adversely affected by the incident. However, all of these tasks require coordinated information provision strategies which the present study aims at addressing.

\section{$1.3 \underline{\text { Study Objectives }}$}

The primary objective of this study is to develop a framework for optimizing system performance under incidents using VMS message content as the control variable. Presumably, if different message contents to describe the same situation prompt different diversion rates, then message content can be used as control variable by the system operator to generate favorable network conditions in the real-time operation of the system while conserving the integrity of information. The framework aims at determining whether and when to activate, modify, or remove VMS advisories. This is done using a dynamic traffic assignment (DTA) based methodology that determines the optimal detour routes and diversion rates, and an incident clearance time prediction model. These are essential inputs to the system operator to effectively manage incidents on-line.

Figure 1.2 illustrates the overall framework for the on-line route advisory and guidance for incident management using VMS. It consists of: 
i) an incident clearance time prediction model which helps in predicting the expected delay due to the incident.

ii) a DTA model which predicts the traffic conditions in response to a particular VMS information provision strategy and can be used to determine VMS strategies that optimize system performance.

iii) a driver behavior model which can predict how drivers respond to different VMS message contents.

The on-line framework is activated by a system operator log that describes the incident by type, location, and number of vehicles involved. This data and other relevant information from the TMC are used by the incident clearance time prediction model to determine the expected duration of the incident. This information is fed to the DTA model to develop effective VMS information provision strategies and predict future traffic conditions. The integrated model, which determines the optimal time-dependent anticipatory information to be provided through the VMS, is incorporated in an on-line detour implementation framework that periodically updates the incident situation in terms of the expected remaining time to clearance. The VMS are deactivated when the effects of the incident(s) on the traffic conditions are no longer significant.

\subsection{Organization of the Report}

This report consists of 6 chapters. Chapter 2 provides a literature review on the real-time use of VMS for congestion and incident management. Chapter 3 presents the 
development and discussion of the incident clearance time prediction models. Chapter 4 discusses the modeling methodology employed for the development of the driver response models, the data collection, and the VMS driver response models estimated. Chapter 5 discusses the methodology to determine the optimal detour routes and VMS diversion rates. Chapter 6 provides some concluding comments and recommendations. 




Figure 1.1 Borman Expressway Network 


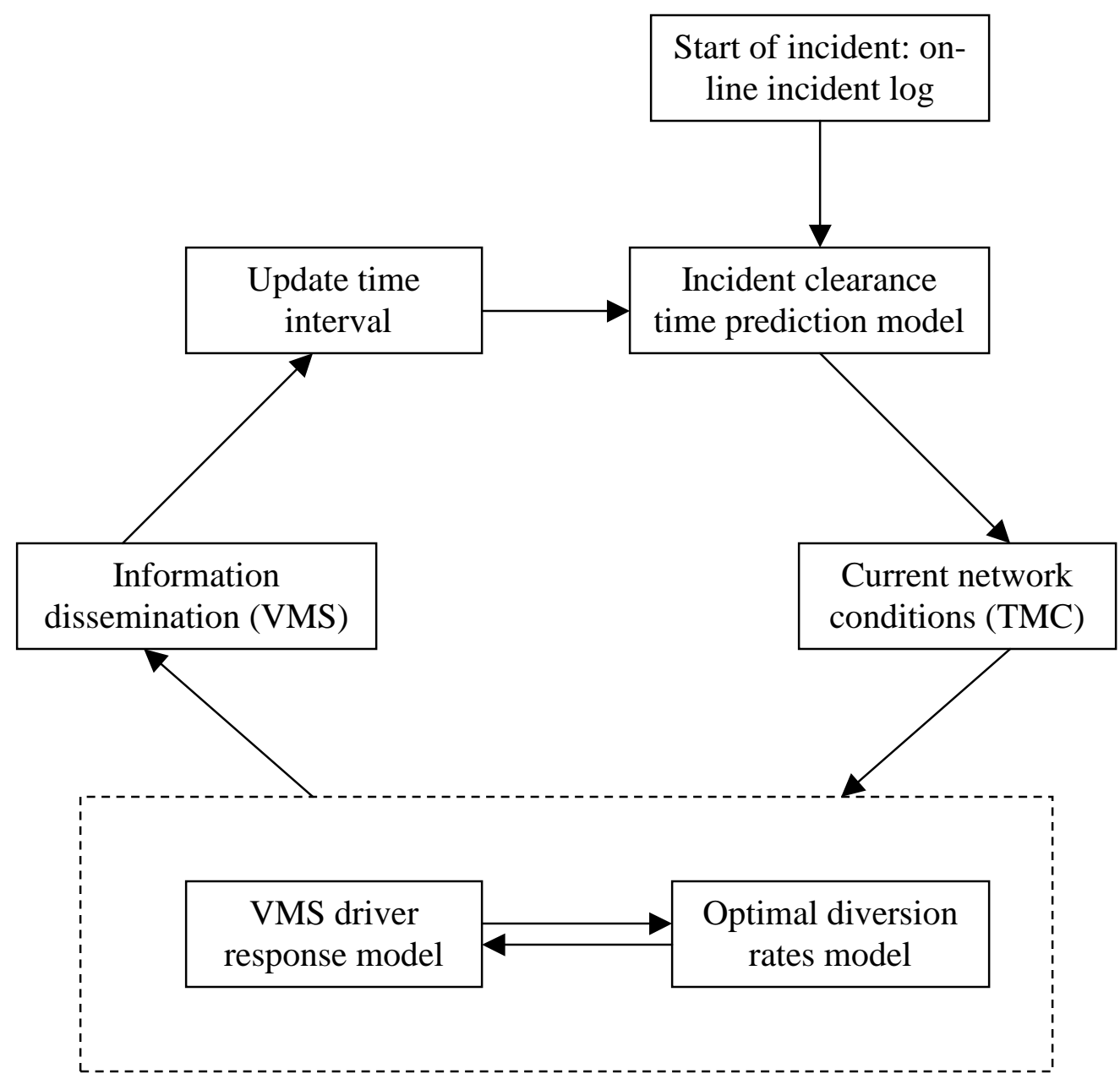

Figure 1.2 On-line Route Advisory and Guidance Framework 


\section{LITERATURE REVIEW}

In the context of ATIS implementation, dynamic traffic assignment (DTA) models [3] aim to capture the dynamic nature of traffic interactions spatially and temporally to optimize system performance (usually in terms of travel cost minimization). They provide systematic operational procedures that can be automated and deployed. The goal of these models is to generate time-dependent routes to assign to drivers that optimize some system-wide objectives while satisfying certain individual user characteristics (in terms of behavioral attitudes and/or goals).

\subsection{Issue of Computational Tractability}

A key deployment issue with dynamic traffic assignment models is their computational intractability. Their execution as part of an on-line traffic control framework requires massive computation which cannot be typically accomplished in subreal time. Past studies have shown that the generation of off-line solutions itself requires substantial computation. Given the convenient and simplifying assumptions on information available on demand and supply conditions in the off-line models, an on-line scenario with its significantly higher complexity due to the need to factor several sources of randomness generates further computational intractability. However, frameworks [4] have been developed to solve the on-line DTA problem by using off-line solution models 
and a truncated planning horizon. These frameworks (such as the rolling horizon approach) tend to alleviate some of the computational burden by simplifying the problem to be solved (typically be truncating the planning horizon and/or circumventing forecasts of future demand/supply), but are still computationally infeasible from a deployment perspective. As stated earlier, off-line DTA algorithms assume static demands and supply conditions that do not accurately reflect the real world conditions. When randomness is factored in, real-world conditions are significantly more accurately depicted, but this introduces another dimension of complexity to the on-line DTA problem. Recent algorithmic developments [5] have addressed this aspect. However, another key issue is the difficulty in capturing user behavior accurately as several behavioral user classes exist in the traffic stream. Hence, an approach that can efficiently (from a computational perspective) achieve system-wide objectives without making restrictive assumptions on user behavior facilitates effective online deployment from the ATIS/ATMS perspective. A VMS-based approach offers this potential.

\subsection{Existing Usage of VMS}

Presently, the most common usage of VMS is to provide current traffic congestion updates, weather-related information, notification of road construction, controlling access to high occupancy vehicle (HOV) lanes, displaying safety messages and notification of public events. VMS, even in a rudimentary form, have been used to disseminate traffic-related information to travelers for more than two decadestheir primary purpose was to control access to HOV lanes. As a result, the VMS were placed 
in locations that are illogical from the perspective of motorist information needs [6]. The strategic location of VMS in the network [7] is an important consideration because it gives the traffic manager efficient control over the system and minimizes the possibility of system deterioration under recurrent and non-recurrent congestion when compared to a rule-of- thumb based location approach.

\section{3 $\underline{\text { Route Guidance using VMS }}$}

Field studies indicate that route guidance using VMS, a recent phenomenon, have a substantially greater potential to improve system performance when compared to VMS displaying passive descriptive information like ambient traffic/weather conditions. Field experiments in the city of Aalborg, Denmark [8] studied how VMS can be best managed to provide relevant reliable information and route guidance to motorists to improve system performance. An automatic control strategy based solely on real-time measurements from loop detectors was employed to achieve this objective. A simplistic rule for calculating travel time was included in the model. The study reported significant improvements to the system performance using this strategy. Studies of user response to VMS on the 600-km freeway network around Paris [9] aimed at modifying individual driver behavior so as to achieve better system performance. In this study, link flow evaluations using loop detector data were performed to estimate the differences in the flow rates with and without VMS. However, traffic flow data analysis was done for a selected link to address issues of user response variation with the type of message displayed on the VMS. 
The primary data sources for VMS are loop detectors embedded in the pavement, closed circuit television cameras, and other ITS traffic surveillance equipment. Dynamic information may also be gathered using probe vehicles reporting their position and speed at regular intervals to the traffic controller. The Aalborg and the Paris experiments relied solely on loop detector data to improve system performance. This raises issues of the accuracy of these analyses because of measurement errors inherent to loop detectors. A more significant drawback of these studies is their lack of transparency to user attitudes towards VMS messages. In a VMS-based approach to optimize system performance it is imperative that the interaction between user VMS response attitudes and the messages displayed on the VMS be considered explicitly because this directly influences network performance. Driver attitudes to messages, in turn, are affected by the current state of the network.. Hence, a fixed-point interaction between user response and network performance exists. This is akin to the fixed-point interaction between path assignments and experienced path travel times from which stems the complexity of the DTA problem and which is also inherited by the VMS problem.

There are additional issues of consistency that need to be considered while solving the VMS problem. User perception of the reliability of the messages displayed on the VMS contributes significantly to any VMS strategy for optimizing system performance. Hence, the messages displayed on the VMS should be consistent from a spatial and temporal perspective. Another deficiency in the state-of-the-art of VMS algorithms is their lack of generality vis-a-vis optimizing system performance. Hence, a key aim of our study is to develop systematic procedures to address these operational issues. 


\subsection{Role of Simulation in Evaluating Effectiveness of VMS}

The effectiveness of VMS messages is difficult to isolate for the following reasons:

(i) the inability to determine what proportion of the flow is actually affected by the message, and

(ii) the variations in the effect of different message contents and format.

While detailed field monitoring of VMS is expensive, an additional difficulty arises in the context of collecting field data on user response behavior to VMS. Experiments are constrained by the traffic controller's reluctance to allow the system to lose credibility by displaying messages that are not appropriate based on the prevailing network conditions or to explore a wide variety of message formats. Research conducted as part of the DRIVE project by the Commission of European Communities R\&D program [12] aimed at predicting the effectiveness of a given message in a given situation through the use of a route choice simulator. This was then used to select that message which has the effect of diverting the desired proportion of traffic - enough to reduce overload at the incident location but not so much as to cause significant problems elsewhere in the network. This study confirmed the important role of simulation studies to pre-screen messages before field application. In our study, simulation was used primarily to evaluate the effectiveness of the proposed VMS algorithm, given an user response model estimated from a stated preference (SP) survey of driver attitudes on the Borman Expressway. 


\section{INCIDENT CLEARANCE TIME PREDICTION MODELS}

Besides the driver response models under VMS-based information, the overall framework for the VMS-based on-line route advisory and guidance for incident management includes an incident clearance time prediction model. In this chapter, incident clearance time prediction models for crashes and roadway debris are estimated using Borman incident data recorded by the Hoosier Helpers.

\subsection{Introduction}

For an ATMS to be effective vis-à-vis non-recurrent congestion, it is crucial to accurately predict traffic delays due to incidents. This implies timely and accurate information on incident delays for increased credibility and effectiveness of traffic information. This motivates the need for estimating incident duration prediction models.

As shown in Figure 3.1, the total incident duration consists of four components: 1) detection and verification time $T_{1}$; this represents the time interval from the occurrence of the incident until the incident is detected and information related to the incident location, type, and severity reaches the TMC;2) dispatch time $\mathrm{T}_{2}$, this is the time elapsed between the identification of the incident and the dispatch of the incident response vehicle (IRV); 3) IRV travel time $\mathrm{T}_{3}$, this is the time that the IRV requires to arrive at the 
incident scene from its previous location; and 4) clearance time $T_{4}$, this is the time between the start of the on-site IRV operation and the end of the clean-up operation. The models estimated in this chapter only predict the fourth component (i.e. clearance time) of the incident duration since data for the other three components is not available.

Incident data from the Hoosier Helper logs was used to update existing Borman incident clearance time prediction models [13]. The existing models were developed using data over a single period, while the models estimated in this Chapter use multiperiod data which aids in the estimation of more accurate models. The models developed in this Chapter are also superior in the sense that they incorporate detailed explanatory variables for weather conditions unlike the previous models. In addition, variables that reflect on incident severity are included to enhance robustness vis-à-vis prediction.

\subsection{Factors Affecting Incident Clearance Time}

The factors that have either direct or indirect influence on incident clearance time are grouped into four major categories: 1) incident characteristics, 2) traffic characteristics, 3) environmental characteristics, and 4) operational characteristics. The incident characteristics include the type of incident, location of incident, and the type and number of vehicles involved. It has been observed that clearance time is longer for incidents involving injuries, more than one vehicle, occurrence of incident on ramps, and occurrence of incidents in work zones. Traffic characteristics include traffic volumes, average traffic speed, and the percentage of trucks at the time of the incident. High volumes of traffic increase the time taken by the IRV to reach the scene. High average 
speeds and high percentage of trucks also prolong the clearance time, as the response crew has to be more cautious about safety. Bad weather conditions such as intense rain and snow hamper the clearance time of incidents. Operational characteristics also affect the clearance time of incidents. They may include the workload of the emergency crew at the time of the incident, the equipment used, and the provision of traffic information to motorists. Notifying motorists on what to expect ahead through VMS and radio traffic reports (RTR) helps in reducing the clearance time since some drivers may divert to alternate routes and reduce the flow in the incident vicinity. This objective is addressed in Chapter 4.

\subsection{Analysis of Data}

An INDOT database containing Hoosier Helper motorist assists from July 1, 1996 to October 28, 1998 is used to develop the incident clearance time prediction models. During this period, the Hoosier Helper completed 22,737 assists, or 26.8 assists per day. The database includes information on the Hoosier Helper arrival and departure time from the scene, the type of incident, and the lateral and longitudinal location of the incident. The incidents are categorized into crash, debris on roadway, or disablement. The last category involves one or more of the following Hoosier Helpers services: changing tire, calling tow trucks, doing minor repairs, supplying gas, aiding overheated vehicles, escorting a motorist, extinguishing fire, waking a sleeping motorist, and providing information. 
A distribution of incident frequency and clearance time by incident type and lateral location of occurrence for the period of July 1996 to October 1998 is presented in Figure 3.2 and Table 3.1. An analysis of these incidents found that disablements, with a mean clearance time of 13.4 minutes, represented $91.1 \%$ of the total number of incidents. Debris on roadway represented $5.2 \%$ of all incidents with a mean clearance time of 4.8 minutes. Crashes had the largest mean clearance time, 33.9 minutes, and comprised 3.7\% of all incidents. For the purpose of comparison, a FHWA study [14] reported that $80 \%$ of freeway incidents recorded by local authorities were disablements, while crashes only made up $10 \%$ of reported incidents.

\subsection{Model Estimation Results}

Linear regression models were estimated for two types of incidents: debris on roadway and crashes. Only these two types of incidents were considered since they are more like to significantly disrupt traffic flow. The Limdep software package [15] was used to estimate the models.

Table 3.2 describes the relevant explanatory variables included in the models. They can be classified into four categories: incident severity variables (NVEH, TRUCK), incident lateral location variables (RAMP, MEDIAN, LL, CL, RL), environmental condition variables (NIGHT, TEMP, VIS, RAINH, RAINL), and current traffic condition variables (RUSH). To the extent that the Hoosier Helper is the system operator, the variables included in the models ensure that the clearance time can be predicted with data accessible by the Hoosier Helper operator, traffic controller, or both. 
There are some key differences between the existing models [13] and the models estimated in this Chapter. First, the updated model for crashes includes variables that indicate the severity of the accident in terms of the number and type of vehicles involved (NVEH and TRUCK). As the number of vehicles involved in the accident increases, the clearance time also increases. The involvement of trucks in crashes results in longer clearing operations. Hence, a truck variable was included as well. Second, the existing models include a variable to indicate if the incident clearance process occurs under adverse weather conditions. However, this variable is rather general. In order to gain richer insights on the effect of weather conditions on the incident clearance process, variables representing rainy and snowy conditions were included. Furthermore, rainy conditions were separated into two categories depending on the intensity of the rain: high intensity rain (RAINH) and low intensity rain (RAINL). The inclusion of these variables allowed the estimation of more refined and accurate clearance time prediction models. The weather data was provided by the Applied Meteorology Group in the Department of Agronomy at Purdue University. They provided an hourly weather database, which made possible the matching with the incident occurrence times. This should represent a reliable weather data source for INDOT in the future.

The estimated models are illustrated in Table 3.3. The data sets for the crashes and debris on roadway incidents included 835 and 1,176 observations, respectively. The model for crashes suggests that the number of vehicles involved in the crash (NVEH) is an important factor (the estimated coefficient has a high t-statistic). The variable TRUCK is not a significant variable. Its low t-statistic may be due to the lack of sufficient observations of severe incidents involving trucks. Also, it is likely that when a 
truck is involved in a crash, the damage done to the truck is insignificant and hence it can be pulled to the shoulder. On the other hand, if the severity of the accident is high (e.g. the truck has overturned), then the immobility of the vehicle increases the time to clear the accident.

In the context of the incident lateral location variables (the base case is the right shoulder), the variable RAMP had the highest coefficient in both models. This could be because the sight distance on freeway ramps is less and the traffic is more difficult to control requiring extra caution by the rescue crew. Being more cautious lends itself to an increase in the clearance time. The same line of reasoning can be extended to variable CL.

The variable NIGHT had a negative coefficient in both models, implying that clean-up operations take longer time during night. TEMP also had a negative coefficient indicating that clearance time of incidents is shorter at high temperatures. At very low temperatures (i.e., during winter months) it is difficult to work outside leading to longer clearance times. As expected, variables RAINH and RAINL were statistically very significant for both the crash and debris on roadway models. The results are intuitive since the coefficient of RAINH is greater than the coefficient of RAINL. The results indicate that high intensity rains hamper the incident clearing process more than low intensity rains. The same line of reasoning can be applied to the variable SNOW. However, this variable was statistically significant only in the debris on roadway model. The lack of statistical significance of SNOW in the crash model may be due to the small number of observations included in the data set under snowy conditions. Although some 
variables had a low t-statistic, they were included in the models because of their potential importance in predicting incident clearance times. An analysis of the appropriateness of the regression models was done. Figures 3.3 and 3.4 show that the residuals, when plotted against the predicted values of the incident clearance time prediction models, do not show any regular pattern and hence the models give unbiased results. 


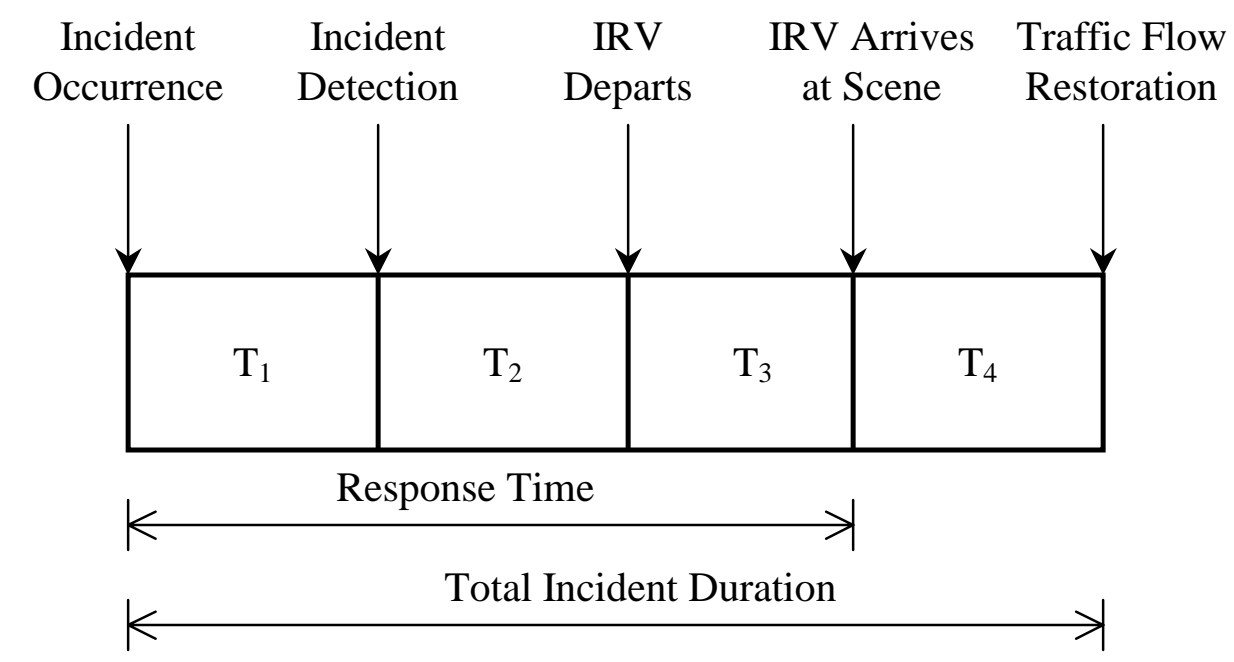

Figure 3.1 Components of Incident Duration 




Figure 3.2 Distribution of Hoosier Helper Assisted Incidents by Type and Lateral Location 


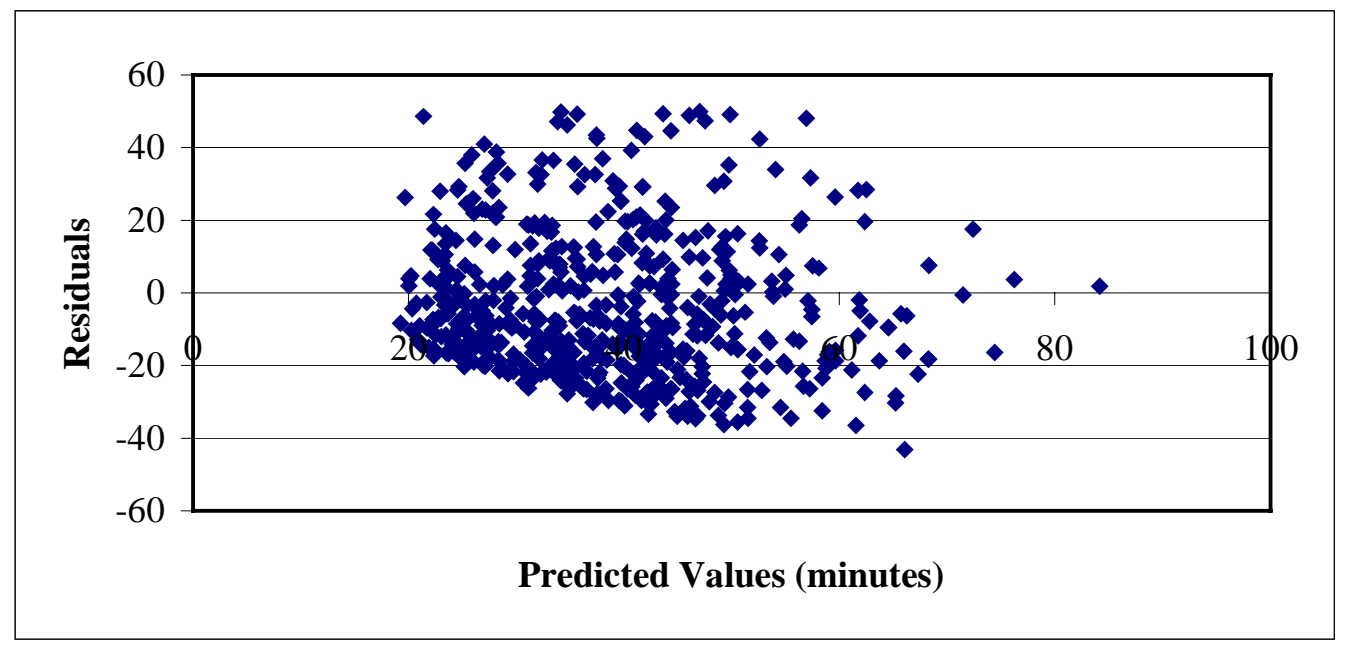

Figure 3.3 Plot of Predicted Values Versus Residuals from Incident Clearance Time Prediction Model of Crash Incidents 


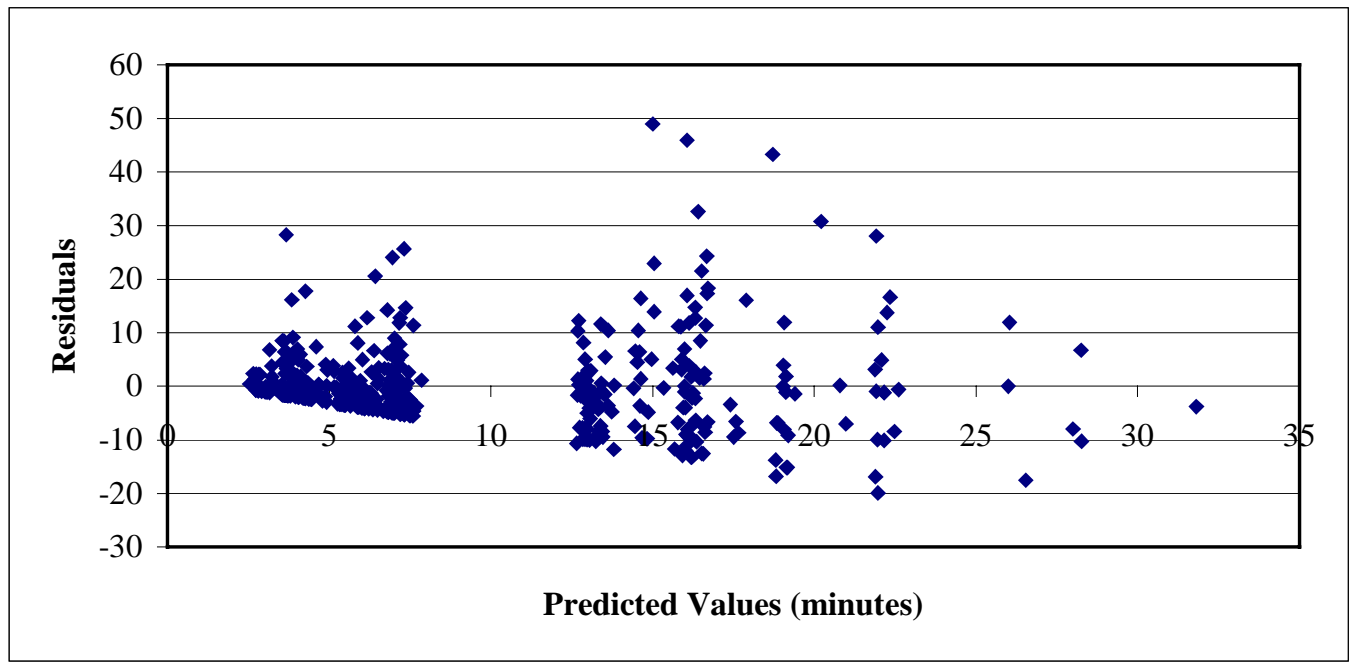

Figure 3.4 Plot of Predicted Values Versus Residuals from Incident Clearance Time Prediction Model of Debris on Roadway 
Table 3.1 Clearance Time of Hoosier Helper Assisted Incidents (Jul. 1996 - Oct. 1998)

\begin{tabular}{lcccccccc}
\hline \multirow{2}{*}{$\begin{array}{l}\text { Incident } \\
\text { Type }\end{array}$} & \multicolumn{9}{c}{$\begin{array}{c}\text { Incident Lateral Location } \\
\text { Median Shoulder }\end{array}$} & \multicolumn{2}{c}{ In-Lane } & \multicolumn{2}{c}{ Right Shoulder } & \multicolumn{2}{c}{ Ramp } \\
\cline { 2 - 10 } & Mean & S.D. & Mean & S.D. & Mean & S.D. & Mean & S.D. \\
\hline Disablements & 14.67 & 17.17 & 19.38 & 22.96 & 10.52 & 13.80 & 11.58 & 16.11 \\
Debris & 24.75 & 31.35 & 4.28 & 8.93 & 7.83 & 12.37 & 6.47 & 16.33 \\
Crashes & 37.39 & 28.85 & 40.95 & 30.17 & 28.69 & 23.15 & 55.12 & 34.25 \\
\hline
\end{tabular}

Note: Mean and standard deviation (S.D.) values are in minutes. 
Table 3.2 Explanatory Variables

\begin{tabular}{|c|c|}
\hline Explanatory Variable & Mnemonic \\
\hline Number of vehicles involved in the incident & NVEH \\
\hline $\begin{array}{l}\text { Median } \\
=1, \text { if incident occurred on the median } \\
=0, \text { otherwise }\end{array}$ & MEDIAN \\
\hline $\begin{array}{l}\text { Left Lane } \\
=1, \text { if incident occurred on the left lane } \\
=0, \text { otherwise }\end{array}$ & LL \\
\hline $\begin{array}{l}\text { Center Lane } \\
=1, \text { if incident occurred on the center lane } \\
=0 \text { otherwise }\end{array}$ & $\mathrm{CL}$ \\
\hline $\begin{array}{l}\text { Right Lane } \\
=1, \text { if incident occurred on the right lane } \\
=0, \text { otherwise }\end{array}$ & RL \\
\hline $\begin{array}{l}\text { Ramp } \\
=1, \text { if incident occurred on the freeway ramp } \\
=0, \text { otherwise }\end{array}$ & RAMP \\
\hline $\begin{array}{l}\text { High intensity rain } \\
=1, \text { if raining with high intensity during the incident } \\
\text { clearance process } \\
=0, \text { otherwise }\end{array}$ & RAINH \\
\hline $\begin{array}{l}\text { Low intensity rain } \\
=1, \text { if raining with low intensity during the incident } \\
\text { clearance process } \\
=0, \text { otherwise }\end{array}$ & RAINL \\
\hline $\begin{array}{l}\text { Snow } \\
=1, \text { if snowing during the incident clearance process } \\
=0, \text { otherwise }\end{array}$ & SNOW \\
\hline $\begin{array}{l}\text { Night } \\
=1, \text { if the incident clearance process occurs at night } \\
=0, \text { otherwise }\end{array}$ & NIGHT \\
\hline $\begin{array}{l}\text { Truck } \\
=1, \text { if a truck is involved in the incident } \\
=0, \text { otherwise }\end{array}$ & TRUCK \\
\hline $\begin{array}{l}\text { RUSH } \\
=1, \text { if the incident occurred during the rush hours } \\
=0, \text { otherwise }\end{array}$ & RUSH \\
\hline
\end{tabular}


Table 3.3 Models for Prediction of Incident Clearance Time

\begin{tabular}{lcc}
\hline \multirow{2}{*}{ Variable } & \multicolumn{2}{c}{ Model } \\
\cline { 2 - 3 } & Coeffeshes & Debris \\
\hline ONE & $12.774(1.989)$ & Coeff. (t-ratio) \\
NVEH & $7.349(4.741)$ & $-120(1.722)$ \\
TRUCK & $2.930(1.199)$ & -- \\
RAMP & $18.055(3.742)$ & $15.677(6.498)$ \\
MEDIAN & $4.496(1.472)$ & $-0.854(-0.212)$ \\
LL & $9.095(2.795)$ & $-0.290(-0.135)$ \\
CL & $15.846(5.054)$ & $9.825(4.780)$ \\
RL & $9.780(2.854)$ & $0.678(0.344)$ \\
NIGHT & $16.596(5.478)$ & $1.730(1.809)$ \\
TEMP & $-0.065(-1.164)$ & $-0.015(-0.741)$ \\
VIS & $-0.136(-0.523)$ & $-0.0001(-0.002)$ \\
RAINH & $32.842(5.094)$ & $13.563(6.619)$ \\
RAINL & $13.571(2.606)$ & $8.487(2.967)$ \\
SNOW & $6.527(1.355)$ & $9.396(2.835)$ \\
RUSH & $-1.150(-0.511)$ & $3.154(3.912)$ \\
Sample Size & 835 & 1176 \\
R $^{2}$ & 0.234 & 0.362 \\
\hline
\end{tabular}




\section{DRIVER BEHAVIOR MODELS FOR THE BORMAN}

This chapter discusses the survey results from data collected on the Borman Expressway in Indiana. In addition, VMS route diversion prediction models are developed for the Borman Expressway region using the survey data. The focus is on developing logit models for estimating the diversion rate in response to a specific VMS message type. A detailed discussion is presented on the estimated parameters for each model.

\subsection{Information-based Route Diversion Behavior}

Information-based route diversion behavior is the outcome of several factors: (i) driver's socioeconomic characteristics, (ii) network state characteristics, and (iii) information characteristics. The socioeconomic characteristics include gender, age, income level, as well as familiarity with the network $[16,17,18,19]$. Socioeconomic characteristics are considered static, that is, they do not change on a day-to-day basis. Network state characteristics include congestion severity and weather conditions. They also can significantly influence driver route diversion decisions [20, 21, 22]. In contrast to the socioeconomic characteristics, these may change on a day-to-day or intra-day basis and hence are considered dynamic. Information attributes also play an important role in 
driver attitudes. Different levels of information may provoke different route diversion rates. Information accuracy is an important factor as well. Discrepancies between the acquired information and the travel experience may lead drivers to rely less on information over time.

Figure 4.1 illustrates the driver response mechanism under information provision. The rectangles correspond to the static characteristics while the trapezoids correspond to the dynamic characteristics. The oval corresponds to the unobservable aspects. The decision-making process is influenced significantly by the feedback in terms of actual experience resulting from the decision. Therefore, a learning process is also involved. However, inertia plays an important role in this learning process as certain thresholds representing a comfort range need to be exceeded before drivers change their habitual behavior.

\section{2 $\underline{\text { VMS Messages }}$}

VMS messages are classified into two categories in terms of their level of persuasion vis-à-vis diversion: passive and active. Passive messages provide information about an incident or traffic congestion only, leaving the course of action to the traveler. They provide information on the type of incident, its location and/or expected delay. Active messages provide instructions on the use of an alternate route to avoid the bottleneck. The passive information can be further classified as qualitative or quantitative. Qualitative information refers to the problem generically (e.g. "ACCIDENT AHEAD") whereas quantitative information focuses on specifics such as the expected 
delay and/or the location of the incident (e.g. "ACCIDENT 2 MI AHEAD, 15 MINUTES DELAY”). From an operator's perspective, passive messages are less complex than active messages in that they are primarily descriptive and inform travelers about ambient traffic conditions. The use of active messages often requires the detection and verification of traffic conditions on the alternate route and the network, increasing the amount of effort required to operate the system. This study analyzes whether route diversion rates differ based on the type and amount of VMS information displayed.

\subsection{User Survey Design}

A stated preference (SP) survey in the form of a questionnaire is conducted in this study to elicit relationships between VMS message content and driver response. The SP methodology is used because it allows researchers to control the explanatory variables [23] and because the main focus of the study is to capture drivers' diversion intentions under a wide range of VMS messages. The revealed preference (RP) approach was not an option because it entails impractical logistic mechanisms like stopping and interviewing motorists on the road after they encounter a VMS message. This also implies that the results would be limited to the messages displayed during the survey period.

The commonly used SP methodology has a number of well-understood limitations. Its main weakness is that subjects may not respond the way they state, in a real situation. In the VMS context, this is primarily because SP cannot effectively capture the situational behavior of users under actual situations characterized by the 
weather, time of day, and ambient traffic conditions. All of these are key situational elements in the driver diversion decision-making process. The ability of the SP methodology to reasonably infer on these factors requires the use of advanced driving simulators capable of recreating driving environments that closely replicate real world conditions (e.g., similar to flight simulators used by the aviation industry to train pilots). However, even if it were possible to use a sophisticated driving simulator, the SP approach is still limited compared to RP in terms of inferring driver actions. Another weakness of the SP methodology is that surveys can be lengthy depending on the key variables that need to be considered. To illustrate this, assume that we are trying to capture the effect of a set of variables $X_{i}(i=1,2,3, \ldots, n)$ on the dependent variable $\mathrm{Y}$ (divert or not divert). Furthermore, assume that each of these $n$ variables have $m$ potential sub-categories. Therefore, there are $m^{n}$ unique combinations of these variables. Ideally, we would like to know the value of the dependent variable for each of the $m^{n}$ unique combinations of variables. In a SP survey, this implies user response to $\mathrm{m}^{n}$ questions.

After identifying the measurable factors that potentially influence route diversion decision under VMS, a SP survey in the form of a questionnaire was designed. The survey questionnaire is illustrated in the Appendix. The first part addresses questions on socioeconomic characteristics such as gender, age, level of education, and household size. The second part elicits their propensity to divert under specific scenarios. In the last part of the questionnaire, the respondents were presented with generic description of VMS messages, and asked whether they would divert to an alternate route. The responses were recorded on a five point Likert scale (1-5), where 1 implies low 
willingness to divert and 5 implies high willingness to divert. Respondents answering 4 or 5 were assumed to divert under that VMS message. The objective of this part was to determine how different levels of information content provided by a VMS influence motorists' propensity to divert. The generic messages are shown in Table 4.1. It should be noted that the messages were specified in a random order in the questionnaire to avoid potential directional bias.

Three survey administration methods were adopted in this study: 1) on-site survey, 2) mail-back survey, and 3) Internet-based survey. The multiple administration approach was used to more effectively sample all segments of the target population. There are advantages and disadvantages of using one method over the other. For example, the on-site method allows the researchers to personally interview the respondents, and hence the responses tend to be more reliable. However, the on-site and the mail-back surveys are time-consuming as data needs to be manually archived in the computer.

The Internet-based survey allows broad access of participants to the survey since it only requires Internet access. There is no need to physically intercept subjects to request their participation. The recruitment process can be done by sending a participation request to randomly selected subjects through electronic mail or regular mail. The respondents' choices are automatically recorded in the server containing the survey, and can be retrieved at a later time by the researcher. Hence, it is less timeconsuming than the other two approaches. Shortcomings of this approach include the 
need for high levels of accessibility of Internet among potential respondents, and overcoming the inertia of having to access a specific Internet address.

\subsubsection{Internet-based Survey}

Internet-based surveys have grown significantly in recent years, providing substantial experience on their design and administration. Access to the questionnaire was provided through a respondent-unique secure point of entry. It is critical to ensure that each respondent has the opportunity to complete only one questionnaire, and that others who are not recruited do not have access to the survey. This is done by providing a password to the target respondents along with the participation request. To ensure that respondents complete only one questionnaire, their computer Internet protocol (IP) address was captured by the server containing the survey using a common gateway interface (CGI) script. An IP address is a series of four numbers, each in the range of 0 to 255, separated by periods, which uniquely identify a computer on the Internet. A Java script is used to ensure that the participant answers all questions before submitting the survey questionnaire.

\subsection{Data Collection}

The target population was travelers on the Borman Expressway. The on-site survey targets commuters, infrequent Borman travelers, and truck drivers on the Borman Expressway. The mail-back survey helps in sampling travelers that use the Borman on a daily basis (commuters). The Internet-based survey targets businesses and individuals 
who value time highly and who as a group entail high refusal rates in mail-back surveys. The survey results from the different administration methods adopted in this study are presented below.

\subsubsection{On-site Survey Results}

Two survey locations were identified for the on-site interview. The first is a truck stop on the Borman Expressway. Hence, most respondents at this location were truck drivers. There are no rest areas on the Borman Expressway. Hence, a rest area on I-65 a few miles south of the Borman was used as the second survey location. The Borman Expressway represents part of the journey for most drivers who stop at this rest area. Most travelers surveyed here were non-truck drivers. The surveys on both locations were conducted using a 4-person crew for two days each. Potential respondents were approached and informed about the objectives of the survey and requested to answer the short questionnaire. The refusal rates were $20 \%$ and $10 \%$ at the truck stop and the rest area, respectively. The data collection effort resulted in 248 observations; 116 truck drivers and 132 non-truck drivers.

Table 4.2 reports the socioeconomic characteristics of the sample. The characteristics are shown for the truck drivers, the non-truck drivers, and for the sample as a whole. About $79 \%$ of the respondents were male. The distribution of the respondents in terms of age groups was mostly even, except for the less than 20 and greater than 65 age groups. 59\% have at least some college experience and $41 \%$ received at least one college degree. $61 \%$ have a household with 3 or more members including 
themselves. The question on the household size was included in this survey because studies have shown that transportation-related decisions are a function of household size $[16,17,19]$. It should be noted that a large proportion of truck drivers belonged to the less-educated category while a large proportion of the non-truck drivers belonged to the well-educated category. Also, most truck drivers were male.

Table 4.3 shows the diversion characteristics of the respondents. About half of the respondents stated that they were regular drivers in the Borman Expressway region. However, this does not necessarily imply that such drivers are familiar with alternate routes other than their regular route. Hence, regular drivers were asked to state their familiarity level with alternate routes. Among this group, $65 \%$ were familiar with at least one alternate route besides the Borman Expressway. $70 \%$ stated that they would divert to an alternate route to avoid unexpected congestion under adverse weather conditions if a VMS message suggested it. This could be due to the effect of incident clearance time. Bad weather conditions may increase the clearance time, persuading drivers to avoid potential excessive delays by diverting to an alternate route. Also, $65 \%$ of the respondents stated that they would divert to an alternate route during night. These results are consistent with the results of previous studies [16] in this region. While the survey obtains responses on weather and time-of-day variables, these responses are not based on the consideration of other relevant factors (such as incident severity) that make driver responses to these variables more meaningful. Such a capability entails providing the respondents several specific situations involving many factors through SP to elicit their response attitudes. As discussed earlier, this is a limitation of the SP approach. Since portable VMS have been in place on the Borman Expressway for a few years, drivers' 
trustworthiness on the information provided was sought in the survey. While $39 \%$ of the drivers stated that they would divert to an alternate route even if they believe that it would be longer than their current route, $29 \%$ stated that they would not. $33 \%$ stated that they were undecided. $71 \%$ stated that they would divert to an alternate route under a work-related trip if that alternate route offered travel time savings ranging from 5 to 30 minutes. However, only $47 \%$ stated that they would divert on a personal trip for identical time savings. This reaffirms the notion of higher value of time for work-related trips.

The driver willingness to divert to an alternate route when different VMS message contents are displayed is summarized in Table 4.4. The responses were obtained in the form of a 5-point Likert scale where ' 5 ' represents a strong willingness to divert and ' 1 ' represents a strong unwillingness to divert. The results indicate that as information content increases, driver propensity to divert also increases provided the information is considered valuable. The results suggest no significant differences in the diversion response to VMS messages 1 and 2. That is, qualitative VMS information such as Occurrence of Accident and Location of the Accident has similar effect on driver propensity to divert. However, quantitative and active messages conveying information on Expected Delay and/or Best Detour Strategy are considered valuable vis-à-vis influencing drivers' route diversion decisions. A shortcoming of using generic VMS messages in the survey is illustrated by the perceived relative values of expected delay and location. While expected delays are perceivable in terms of magnitude, the value of location is perceivable only in actual situations or specifically constructed SP scenarios. In reality, the incident location can represent valuable information under many real situations. 


\subsubsection{Mail-back Survey Results}

The mail-back questionnaire was sent to 3,660 randomly selected households and businesses in the Borman Expressway region. The survey included a brief explanation of the purpose of the survey, the questionnaire, and a reply envelope. A total of 402 residents and businesses responded, which represents a response rate of about $11 \%$.

Table 4.5 reports the socioeconomic characteristics of the sample. Among the respondents, 59\% were male. Compared to the on-site survey sample, there is a greater female representation in the mail-back survey sample. The distribution of the respondents in terms of age group is skewed towards the older age groups; $73 \%$ of the subjects were older than 40 years. This is different from the on-site survey where the distribution is more uniform. $55 \%$ have at least some college experience and $45 \%$ received at least one college degree. In terms of the level of education, there is no statistical difference between the on-site survey and the mail-back survey samples.

Table 4.6 illustrates the diversion attitudes of the mail-back survey sample. During the design of the on-site survey, it was assumed that Borman users were not familiar with VMS. However, several on-site survey respondents stated that they were familiar with VMS. Therefore, the mail-back questionnaire survey, which was conducted later, included a question on drivers' familiarity with VMS. The survey shows that $84 \%$ of the respondents have experience with VMS. This high percentage is because most respondents are daily commuters in the Borman Expressway region and, hence, are familiar with the portable VMS that have been in place on the Borman for a few years. However, the portable VMS are currently used to inform users on roadwork and traffic conditions at the simplest information level. Almost $81 \%$ of the respondents stated that 
they were regular drivers on the Borman Expressway. This percentage is higher compared to the on-site survey because the sample from the mail-back survey is mostly composed of Borman commuters. Among regular drivers, $90 \%$ indicated that they were familiar with alternate routes besides the Borman Expressway. Although the survey attempts to capture the effect of the magnitude of delay on the propensity to divert, the ratio of this delay to the expected trip time may be a more robust explanatory variable. Therefore, a question on the respondents' average commute time was included in the mail-back questionnaire. $50 \%$ experience an average commute time less than 30 minutes, $26 \%$ experience between 30 to 60 minutes, $10 \%$ experience more than 60 minutes, and $14 \%$ are either unemployed or retired. Akin to the on-site survey, most respondents stated that they would divert to an alternate route to avoid unexpected traffic delay under adverse weather conditions or during the night. When asked if they would divert to an alternate route if a VMS suggested it, even if they believe that it would be longer than their current route, $39 \%$ stated that they would divert, $30 \%$ were undecided, and $31 \%$ stated that they would not divert. The distribution of the responses to this question is almost identical to that under the on-site survey. $84 \%$ of the participants stated that they would divert to an alternate route under a work-related trip if the alternate route offered travel time savings ranging from 5 to 30 minutes, while $75 \%$ stated that they would divert under a personal trip for identical time savings. The difference $(9 \%)$ between drivers diverting under work-related trips and personal trips is lesser than the difference $(24 \%)$ from the results of the on-site survey. This is consistent with the responses to the question on the amount of delay that would convince drivers to divert. In the on-site survey, $53 \%$ stated that they would divert to an alternate route when the delay ranges 
from 5 to 30 minutes, while in the mail-back survey $82 \%$ would divert for the same range of delay.

Table 4.7 summarizes the willingness to divert to an alternate route when different VMS message contents are displayed. The results are consistent with those of the on-site survey, that is, driver propensity to divert increases as level of detail in the information increases. The results suggest no significant difference in the diversion response to VMS message types 3 and 4, and between 6 and 7. The Best Detour Strategy and the Location of Accident have added value only in conjunction with information on Expected Delay and Best Detour Strategy.

In addition to the questions on driver propensity to divert under specific scenarios, the mail-back survey included an optional question to answer which asked respondents to state any comments on VMS and what message might be useful for them. The most common comment was that the VMS should graphically display the lane(s) affected by the incident. Another common suggestion was that VMS should also be installed on arterials so that information on traffic congestion is available before entering the freeway ramp. Finally, a significant amount of the respondents stated that if route guidance is provided, the freeway off-ramp number should be displayed on the VMS.

\subsubsection{Internet-based Survey Results}

The Internet-based survey participants were recruited through e-mail. 880 e-mail addresses of residents in the Borman Expressway region and 125 e-mail addresses of businesses in the area were used to target potential survey participants. The sample consists of 29 residents and 5 businesses. This represents a response rate of $4.4 \%$ and 
4.7\% for the residents and businesses, respectively. The overall response rate, factoring in invalid addresses, is $3.5 \%$. The survey was implemented on the URL http://www.ecn.purdue.edu/Action/Survey/index.htm.

The socioeconomic characteristics of the sample are illustrated in Table 4.8. About $74 \%$ of the respondents were male. This distribution compares quite well with that of the on-site survey. Most participants (82\%) are less than 40 years old. In addition, the majority of the respondents (79\%) received at least one college degree. $21 \%$ have some college experience. Hence, the sample is biased towards young and welleducated persons.

The sample diversion characteristics are summarized in Table 4.9. Since the survey targeted residents and businesses in the Borman Expressway region, the results are similar to those obtained in the mail-back survey. Almost all the respondents (97\%) are regular drivers in the Borman Expressway region and are familiar with at least one alternate route besides their regular one. A notable difference between the Internet-based survey and the other two surveys is in the context of the driver's trust in the traffic information provided. In the Internet-based survey, $47 \%$ of the respondents stated that they would divert to an alternate route even if they believed that it would be longer than their current route. Since the majority of the participants in the Internet-based survey are well-educated individuals, they are likely to be more at ease with technological innovations, and hence may exhibit lesser inertia and a greater level of compliance with VMS-based information. Table 4.10 summarizes the willingness to divert to an alternate route under different VMS message contents. They are consistent with those obtained in the other two surveys. 


\subsection{Driver Behavior Model Structure}

The choice set $C_{n}$ of each individual consists of only two alternatives (divert or not divert), motivating the use of a binary logit model to predict the probability of a user diverting under a VMS message. The utility functions are represented by:

$U_{i n}=V_{i n}+\varepsilon_{i n}$

$U_{j n}=V_{j n}+\varepsilon_{j n}$

where:

$i=$ alternative representing user diverting,

$j=$ alternative representing user not diverting,

$V_{\text {in }}=$ systematic component of the utility of diverting from the current route,

$V_{j n}=$ systematic component of the utility of not diverting from the current route, and

$\varepsilon_{i n}$ and $\varepsilon_{j n}=$ disturbances or random components.

The probability of an individual $n$ diverting is equal to the probability that the utility of alternative $i, U_{i n}$, is greater than or equal to the utility of alternative $j, U_{j n}$. This can be written as follows:

$P_{n}\left(i \mid C_{n}\right)=\operatorname{Pr}\left[U_{i n} \geq U_{j n}, \forall j \in C_{n}\right]$

Then, the probability of user $n$ diverting is given by:

$P_{n}(i)=\frac{1}{1+e^{-\left(V_{i n}-V_{j n}\right)}}$

The difference in the systematic components is represented as follows:

$V=\left(V_{i n}-V_{j n}\right)=O N E+\beta X+\alpha V M S$

where: 
$O N E=$ alternative specific constant corresponding to divert,

$X=$ vector of those explanatory variables other than VMS message type that may influence a driver's decision to divert,

$\beta=$ vector of estimated parameters corresponding to $X$,

$V M S$ = vector of dummy explanatory variables representing each of the VMS message types provided to drivers, and

$\alpha=$ vector of estimated parameters corresponding to $V M S$.

The third element of the right hand side of equation [4.5] is represented as:

$$
\alpha V M S=\sum_{k=2}^{8} \alpha_{k} V M S_{k}
$$

where:

$\alpha_{k}=$ coefficient of $V M S_{k}$, and

$V M S_{k}=$ dummy variable representing VMS message $k$.

The explanatory variables included in the utility function are shown in Table 4.11. The survey data was used to estimate the logit models, which are then icorporated into the VMS-based on-line route advisory and guidance framework.

\subsection{Analysis of Models}

Logit models are developed using the survey data. The Maximum Likelihood Estimation (MLE) procedure was used to estimate the parameters of the models. The Limdep software package [15] was used to estimate the parameters of the models. 


\subsubsection{Estimation Using the On-site Survey Data}

As a first step in the model building procedure, a General model was constructed with the on-site survey data $(8 \mathrm{VMS}$ message types per person $\times 248$ respondents $=1984$ pooled observations). The second column in Table 4.12 shows the estimation results of this General model. All variables were included in the initial estimation procedure. However, variables found to be insignificant in the intermediate models were omitted at the corresponding stages. Also, the categories shown in Table 4.11 for some variables


survey subcategories that were not statistically different.

The variable ONE is the alternative specific constant. It represents the utility of diverting for a driver exposed to $\mathrm{VMS}_{1}$, and whose socioeconomic and other characteristics are given by the base cases (represented by the zero values in Table 4.8). The negative sign is indicative of a natural aversion or inertia to diversion. It illustrates that the potential for "convincing" more drivers to divert exists through different VMS message contents (compared to $\mathrm{VMS}_{1}$ ). When any of the message types $\mathrm{VMS}_{1}, \mathrm{VMS}_{2}$, $\mathrm{VMS}_{3}$ or $\mathrm{VMS}_{4}$ are displayed, there is no combination of socioeconomic variables that will produce a positive utility difference. A pair-t-test [25] at the significance level of 5\% showed no statistical differences between VMS messages 1 through 4, suggesting that motorists exhibit an inclination to stay on their current route when they do not have detailed information on the incident. This reaffirms the conclusions of previous studies $[16,17,19]$.

SEX and AGE are important socioeconomic characteristics that influence the diversion behavior of an individual. SEX has a positive sign implying that males are 
more likely to divert than females under similar conditions. AGE has a negative coefficient indicating that younger drivers are more likely to divert than older drivers. These results are consistent with previous studies [16, 19], that indicate that females and older drivers are more risk averse than males and younger drivers, respectively.

The model also suggests that the education level (EDU) of a driver may be an important factor influencing his/her diversion decisions. Well-educated individuals exhibit greater compliance with VMS as compared to their less-educated counterparts under similar conditions. Education is a well-known proxy for the income level of a person [26]. Therefore, well-educated people are likely to value time more and may be more sensitive to delays on their planned route. Another reason for the significance of the EDU variable relates to the level of comfort with technology. Well-educated individuals are at greater ease with technological innovations, at least initially, and hence may not exhibit as much inertia to VMS messages. A related issue is that most truck drivers belong to the less-educated category. Therefore, EDU could act as a proxy for truck drivers. This becomes evident when estimating models for the non-truck drivers separately.

Dummy variables corresponding to VMS messages 3 through 8 were included in all models $\left(\mathrm{VMS}_{1}\right.$ is the base case). The $\mathrm{VMS}_{k}$ variables are very significant and provide the largest increases in log-likelihood among all variables. As discussed in section 4.3, VMS messages from 1 through 8 are in the order of increasing amounts of information. In all models, coefficient values increase with information, implying that more relevant information displayed on a VMS leads to higher diversion propensity. These results are 
important because they suggest that driver diversion behavior can be influenced by controlling the amount of information displayed on the VMS. The traffic controller could use this variable to improve network performance without impinging on the information veracity. The model suggests no statistical difference between messages $\mathrm{VMS}_{1}$ and $\mathrm{VMS}_{2}$, implying the lack of value for the location of the incident. Hence, the variable $\mathrm{VMS}_{2}$ was not included in the model. This highlights the limitations of the SP approach in the VMS context. Location plays a significant role in diversion decisions based on the actual destination. However, unlike expected delay magnitude, which can be perceived irrespective of the actual situation, the value of the location of an incident is revealed only in real situations. Hence, the lack of statistical differences between one or more VMS variables might be an artifice of the SP methodology as opposed to a behavioral effect.

To explore whether significant differences exist in the response attitudes of truck drivers compared to other travelers, the survey data was separated into truck and nontruck observations and separate binary logit models were estimated for them. The diversion behavior of truck drivers could be significantly different from that of non-truck drivers because not all alternate routes available to a non-truck driver are feasible for trucks. Hence, truck drivers may exhibit more resistance to diversion than other drivers. The results are illustrated in Table 4.12.

The major difference between the Truck and Non-Truck models is the effect of the variables DRIV (regular driver) and FAM (familiarity with alternate routes). These variables are significant for truck diversion, but not for non-truck diversion, suggesting 
that being a regular driver and being familiar with alternate routes is important for truck drivers vis-à-vis route diversion decisions. This implies that they may a priori hesitate to consider all alternate routes as legitimate alternatives. Therefore, unless a truck driver is familiar with alternate routes, he/she may not risk diverting. The variable TRUST is an important explanatory variable in all three models (General, Truck, Non-Truck). It has a positive sign indicating that people who trust the messages displayed on the VMS are more amenable to diverting as compared to those who do not.

The trends in the $\mathrm{VMS}_{k}$ variables for the Truck and Non-Truck models are similar to those observed in the General model. There is a small decrease in coefficient values from $\mathrm{VMS}_{6}$ to $\mathrm{VMS}_{7}$ in the Truck model. However, these messages are statistically different as determined from a pair-t-test at the $95 \%$ confidence level. For the Truck model, $\mathrm{VMS}_{2}$ and $\mathrm{VMS}_{3}$ are not statistically different from the base case $\left(\mathrm{VMS}_{1}\right)$. Similarly, for the Non-Truck model there is no statistical difference between $\mathrm{VMS}_{1}$ and $\mathrm{VMS}_{2}$ as determined from a likelihood ratio test. These are possibly because of the limitations of the SP methodology, as discussed earlier.

So far the specific trends for the Truck and Non-Truck models have been discussed. However, the models cannot compare their coefficients. For instance, is the effect of TRUST on diversion probability different for truck and non-truck drivers? To answer such questions, the truck and non-truck data were pooled and a combined model with interaction variables was estimated, as shown in Table 4.12.

The effect of age on diversion propensities is similar for truck and non-truck drivers, and is hence not a significant interaction variable. As discussed earlier, DRIV 
and FAM are important factors for truck drivers. Hence, (DRIV*TRUCK) and (FAM*TRUCK) are significant variables in this model. Also, the effect of the TRUST variable seems to differ for truck and non-truck drivers. From Table 4.9, the TRUST variable has a coefficient value of 0.924 and the interaction variable (TRUST*TRUCK) has a coefficient value of -0.525 . Hence, the contribution of the TRUST variable will be $(0.924-0.525)=0.399$ for a truck driver but 0.924 for a non-truck driver. The positive sign for the combined coefficient (0.399) for truck drivers implies that trusting truck drivers exhibit a higher diversion propensity compared to non-trusting ones. Also, since 0.399 is less than 0.525 (TRUST), it suggests that trusting truck drivers exhibit a slightly lower propensity to divert than trusting non-truck drivers. Hence, the TRUST variable does not have similar effects on truck and non-truck drivers. The same line of reasoning can be extended to the VMS interaction variables. ( $\left.\mathrm{VMS}_{3} * \mathrm{TRUCK}\right),\left(\mathrm{VMS}_{5} * \mathrm{TRUCK}\right)$ and $\left(\mathrm{VMS}_{7} * \mathrm{TRUCK}\right)$ are all negative. This implies that if the message $\mathrm{VMS}_{3}, \mathrm{VMS}_{5}$, or $\mathrm{VMS}_{7}$ is shown, a truck driver is less likely to divert than a corresponding non-truck driver. It highlights the greater importance of location for truck drivers. However, when one of the other VMS messages is displayed, there is no significant difference in their diversion probabilities.

These findings are important in the context of commercial highway corridors such as the Borman Expressway where trucks represent a significant fraction of the total traffic. An important issue that needs to be considered in this regard in the VMS advisory and route guidance on-line framework is the strategy adopted for trucks and other CVO operations. Due to the size of trucks, certain routes are infeasible due to capacity and geometry constraints. Also, trucks may be precluded from using certain 
streets by the traffic controller for safety reasons. To address this problem, the VMS online framework should be capable of identifying alternate routes that are truck-safe. Specific VMS messages should be displayed for truck drivers to inform them of feasible alternate routes. In the Borman Expressway region, two alternative truck-safe routes have been identified: US-30 and I-90. The latter is a toll road and hence may incur some resistance as an alternative route. However, since it is an interstate highway, it can potentially absorb relatively large diversions from the Borman. US-30, another potential diversion route has several signalized intersections. During the on-site survey, truck drivers expressed reluctance to divert to this route because of the delays due to signals and the effort involved in truck operation at low speeds. Hence, there are advantages and disadvantages to each alternative diversion route.

\subsubsection{Estimation Using the Mail-back Survey Data}

The logit model estimated using the mail-back survey data is presented in Table 4.13. All variables were included in the estimation procedure. Variables determined as being insignificant in intermediate models were omitted at the corresponding stages. The variable DRIV has a positive sign implying that regular drivers in the Borman Expressway region are more likely to divert. This is consistent with the survey since $84 \%$ of the survey participants use the Borman Expressway regularly. Since the survey targeted residents and businesses in the Borman Expressway region, respondents are familiar with at least one alternate route besides the Borman. This is reflected in the high explanatory power of the variable FAM. The model also suggests that individuals whose average work commute time is more than 30 minutes are more likely to divert under 
unexpected traffic congestion. This is because drivers with longer travel times have greater opportunities to switch routes. As before, the variable TRUST is an important explanatory variable. Delay thresholds were investigated in this study by incorporating different expected delay ranges in the survey. They were categorical and were represented by a dummy variable (DELAY) at the 10 minute threshold which was the only statistically significant one. The model indicates that drivers are more likely to divert if the expected delay is at least 10 minutes. This is important in the context of designing VMS information strategies, implying that it would be better to incorporate a delay threshold and display diversion advice only if the threshold is exceeded. The trends in the VMS variables are similar to those in the on-site survey based models. There is a small drop in the coefficient values from $\mathrm{VMS}_{3}$ to $\mathrm{VMS}_{4}$, but difference is not statistically significant as determined from the pair-t-test. This suggests that explicit information on delays is valuable to drivers.

\subsubsection{Estimation Using the Internet-based Survey Data}

The logit model for driver response under VMS using the Internet-based survey data is presented in Table 4.14. It should be noted here that the number of sample observations for this survey is small compared to those for the other two surveys. In the context of the socioeconomic variables, the results are consistent with those obtained in the previous models. A major difference is that the variable TRUST is not a significant variable and hence was not included in the model. The low statistical significance for this variable might be to the high level of education of the survey respondents $(79 \%$ received at least one college degree). Well-educated individuals are likely to be more at 
ease with technological innovations and hence may exhibit greater compliance with VMS-based information. The trends in the $\mathrm{VMS}_{k}$ variables are similar to those observed in the on-site and mail-back sample models.

\subsubsection{Combined Data Estimation}

Three survey administration methods were used in this study to elicit relationships between the VMS message content and driver response. As stated earlier, the multiple administration approach allows sampling the various segments of the target population more effectively. Therefore, a model combining the data collected from the on-site, mailback, and Internet-based surveys was estimated. It is illustrated in Table 4.15. The results lead to similar conclusions as in the previous models. Most socioeconomic variables were not statistically significant and hence were not included in the model. 


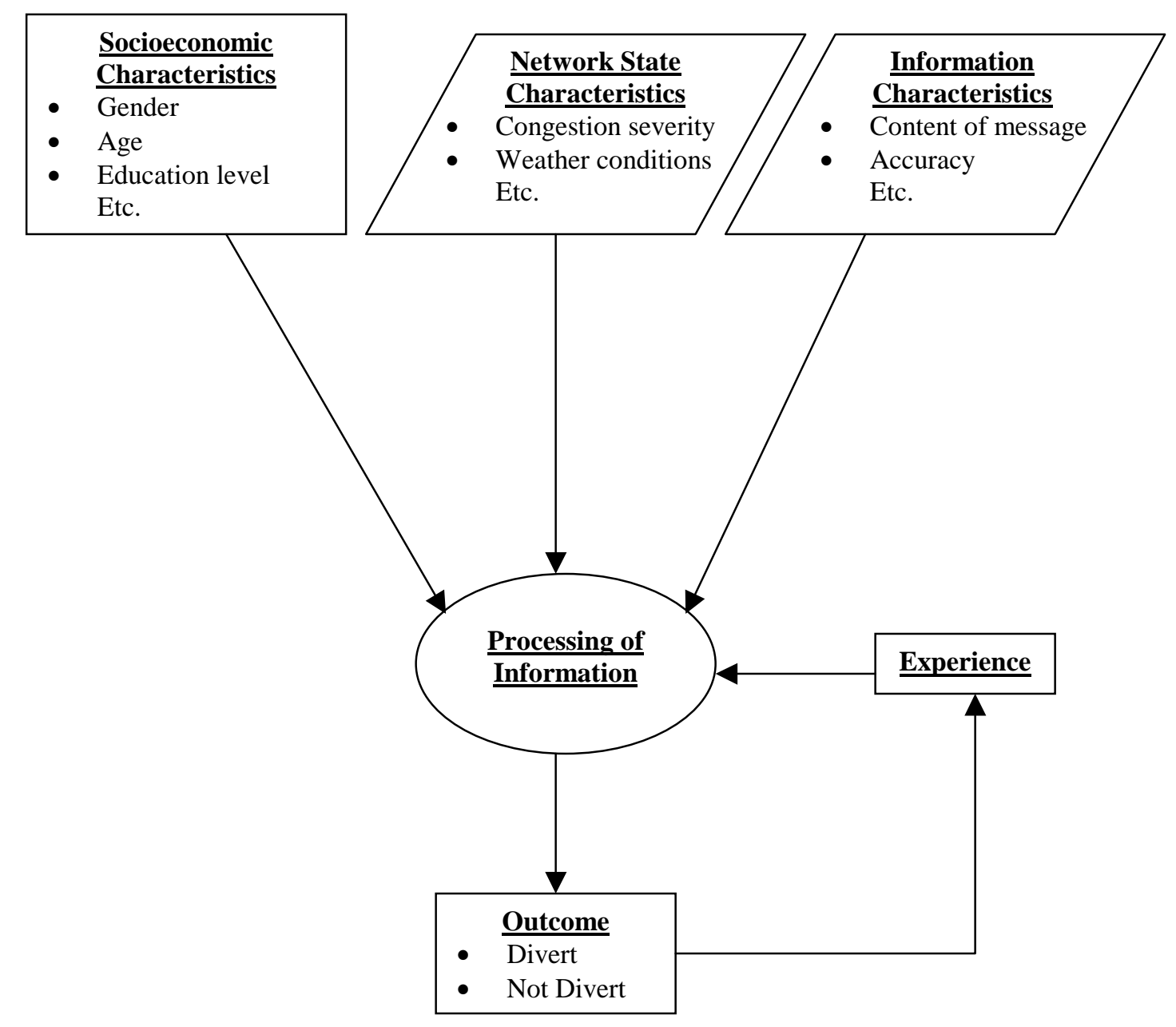

Figure 4.1 Driver Response Mechanism Under Information Provision 
Table 4.1 VMS Message Content

\begin{tabular}{ccl}
\hline VMS & Category & \multicolumn{1}{c}{ Message Content } \\
\hline 1 & Qualitative & Occurrence of accident only \\
2 & Qualitative & Location of the accident only \\
3 & Quantitative & Expected delay only \\
4 & Prescriptive & The best detour strategy only \\
5 & Prescriptive & Location of the accident and the best detour strategy \\
6 & Quantitative & Location of the accident and the expected delay \\
7 & Prescriptive & Expected delay and the best detour strategy \\
8 & Prescriptive & $\begin{array}{l}\text { Location of the accident, expected delay, and the best } \\
\text { detour strategy }\end{array}$ \\
\hline
\end{tabular}


Table 4.2 Socioeconomic Characteristics of the On-site Survey Sample

\begin{tabular}{llccc}
\hline Attribute & Range & $\begin{array}{c}\text { Non-truck } \\
\text { Drivers }(\%)\end{array}$ & $\begin{array}{c}\text { Truck } \\
\text { Drivers (\%) }\end{array}$ & $\begin{array}{c}\text { Aggregate } \\
(\%)\end{array}$ \\
\hline Gender & Male & 63.6 & 95.7 & 78.6 \\
& Female & 36.4 & 4.3 & 21.4 \\
Age Group & & & & \\
& $20-29$ & 4.5 & 2.6 & 3.6 \\
& $30-39$ & 21.2 & 26.7 & 23.8 \\
& $40-49$ & 28.0 & 27.6 & 27.8 \\
& $50-64$ & 22.7 & 24.1 & 23.4 \\
& $\geq 65$ & 12.9 & 15.5 & 14.1 \\
Education Level & High School or less & 10.6 & 3.4 & 7.3 \\
& Some College & 15.2 & 35.3 & 26.2 \\
& College Graduate & 40.2 & 12.1 & 32.7 \\
& Post Graduate & 26.5 & 0.0 & 14.1 \\
& & & & \\
Persons in Household & 1 & 17.4 & 11.2 & 14.5 \\
& 2 & 26.5 & 22.4 & 24.6 \\
& 3 & 25.0 & 22.4 & 23.8 \\
& & 31.1 & 44.0 & 37.1 \\
\hline
\end{tabular}


Table 4.3 Diversion Characteristics of the On-site Survey Sample

\begin{tabular}{|c|c|}
\hline Sample Attributes & Frequency $(\%)$ \\
\hline \multicolumn{2}{|c|}{ Regular driver on the Borman Expressway } \\
\hline Yes & 50.4 \\
\hline No & 49.6 \\
\hline \multicolumn{2}{|c|}{ Familiarity with alternate routes } \\
\hline Very familiar & 32.8 \\
\hline Familiar & 32.0 \\
\hline Undecided & 13.6 \\
\hline Not familiar & 17.6 \\
\hline Not familiar at all & 4.0 \\
\hline \multicolumn{2}{|c|}{ Diverting under adverse weather conditions } \\
\hline Yes & 73.8 \\
\hline No & 26.2 \\
\hline \multicolumn{2}{|l|}{ Diverting at night } \\
\hline Yes & 65.3 \\
\hline No & 34.7 \\
\hline \multicolumn{2}{|c|}{$\begin{array}{l}\text { Diverting even when believing that alternate } \\
\text { route would be longer }\end{array}$} \\
\hline Strongly agree & 8.5 \\
\hline Agree & 30.2 \\
\hline Undecided & 32.7 \\
\hline Disagree & 16.5 \\
\hline Strongly disagree & 12.1 \\
\hline \multicolumn{2}{|c|}{ Travel time savings under work-related trip } \\
\hline 5-10 min. & 22.6 \\
\hline $10-30 \mathrm{~min}$. & 48.0 \\
\hline $30-60 \mathrm{~min}$. & 20.6 \\
\hline More than $60 \mathrm{~min}$. & 3.6 \\
\hline None & 5.2 \\
\hline \multicolumn{2}{|c|}{ Travel time savings under personal trip } \\
\hline $5-10$ min. & 9.7 \\
\hline $10-30 \mathrm{~min}$. & 37.5 \\
\hline $30-60 \mathrm{~min}$. & 38.3 \\
\hline More than $60 \mathrm{~min}$. & 10.1 \\
\hline None & 4.4 \\
\hline \multicolumn{2}{|l|}{ Delay before diverting } \\
\hline 5-10 min. & 12.9 \\
\hline $10-30 \mathrm{~min}$. & 39.9 \\
\hline $30-60 \mathrm{~min}$. & 35.9 \\
\hline More than $60 \mathrm{~min}$. & 10.1 \\
\hline None & 1.2 \\
\hline
\end{tabular}


Table 4.4 Effect of VMS Message Content (On-site Survey Sample)

\begin{tabular}{|c|c|c|c|c|c|c|}
\hline \multirow{3}{*}{$\begin{array}{c}\text { VMS } \\
\text { Message } \\
\text { Type }\end{array}$} & \multirow{3}{*}{ Message Content } & \multicolumn{5}{|c|}{ Relative Willingness to Divert } \\
\hline & & 1 & 2 & 3 & 4 & 5 \\
\hline & & $\%$ & $\%$ & $\%$ & $\%$ & $\%$ \\
\hline 1 & Occurrence of accident only & 13.7 & 33.9 & 26.6 & 13.3 & 12.5 \\
\hline 2 & Location of the accident only & 20.2 & 33.1 & 22.6 & 11.3 & 12.9 \\
\hline 3 & Expected delay only & 9.3 & 12.9 & 39.5 & 23.8 & 14.5 \\
\hline 4 & The best detour strategy only & 7.7 & 18.5 & 30.2 & 25.0 & 18.5 \\
\hline 5 & $\begin{array}{l}\text { Location of the accident and the best detour } \\
\text { strategy }\end{array}$ & 2.0 & 4.0 & 22.6 & 35.1 & 36.3 \\
\hline 6 & $\begin{array}{l}\text { Location of the accident and the expected } \\
\text { delay }\end{array}$ & 0.8 & 0.8 & 19.8 & 38.3 & 40.3 \\
\hline 7 & Expected delay and the best detour strateg & 2.0 & 2.0 & 13.7 & 33.5 & 48.8 \\
\hline 8 & $\begin{array}{l}\text { Location of the accident, expected delay, and } \\
\text { the best detour strategy }\end{array}$ & 1.2 & 2.0 & 5.6 & 19.8 & 71.4 \\
\hline
\end{tabular}


Table 4.5 Socioeconomic Characteristics of the Mail-back Survey Sample

\begin{tabular}{llc}
\hline Attribute & Range & Percentage \\
\hline Gender & Male & 58.5 \\
& Female & 41.5 \\
\multirow{4}{*}{ Age Group } & $<20$ & \\
& $20-29$ & 0.0 \\
& $30-39$ & 8.5 \\
& $40-49$ & 18.4 \\
& $50-64$ & 27.3 \\
& $\geq 65$ & 29.9 \\
Education Level & High School or less & 15.9 \\
& Some College & 24.7 \\
& College Graduate & 30.5 \\
& Post Graduate & 26.4 \\
& & 18.4 \\
Persons in Household & 1 & 17.0 \\
& 2 & 40.1 \\
& 3 & 14.6 \\
& $\geq 4$ & 28.3 \\
\hline
\end{tabular}


Table 4.6 Diversion Characteristics of the Mail-back Survey Sample

\begin{tabular}{|c|c|}
\hline Sample Attributes & Frequency $(\%)$ \\
\hline \multicolumn{2}{|l|}{ Familiar with VMS } \\
\hline Yes & 84.1 \\
\hline No & 15.9 \\
\hline \multicolumn{2}{|c|}{ Regular driver on the Borman Expressway } \\
\hline Yes & 80.8 \\
\hline No & 19.2 \\
\hline \multicolumn{2}{|c|}{ Familiarity with alternate routes } \\
\hline Very familiar & 59.7 \\
\hline Familiar & 29.9 \\
\hline Undecided & 4.2 \\
\hline Not familiar & 6.2 \\
\hline Not familiar at all & 0.0 \\
\hline \multicolumn{2}{|c|}{ Average work commute time } \\
\hline 5-10 min. & 15.5 \\
\hline $10-30 \mathrm{~min}$. & 34.4 \\
\hline $30-60 \mathrm{~min}$. & 26.2 \\
\hline More than 60 min. & 10.0 \\
\hline None & 13.9 \\
\hline \multicolumn{2}{|c|}{ Diverting under adverse weather conditions } \\
\hline Yes & 89.5 \\
\hline No & 10.5 \\
\hline \multicolumn{2}{|l|}{ Diverting at night } \\
\hline Yes & 66.9 \\
\hline No & 33.1 \\
\hline \multicolumn{2}{|c|}{$\begin{array}{l}\text { Diverting even when believing that alternate } \\
\text { route would be longer }\end{array}$} \\
\hline Strongly agree & 6.3 \\
\hline Agree & 32.5 \\
\hline Undecided & 30.4 \\
\hline Disagree & 18.6 \\
\hline Strongly disagree & 12.1 \\
\hline \multicolumn{2}{|c|}{ Travel time savings under work-related trip } \\
\hline $5-10$ min. & 35.7 \\
\hline 10-30 min. & 48.3 \\
\hline $30-60 \mathrm{~min}$. & 9.4 \\
\hline More than $60 \mathrm{~min}$. & 0.5 \\
\hline None & 6.0 \\
\hline \multicolumn{2}{|c|}{ Travel time savings under personal trip } \\
\hline 5-10 min. & 21.5 \\
\hline 10-30 min. & 53.3 \\
\hline 30-60 min. & 18.9 \\
\hline More than $60 \mathrm{~min}$. & 4.7 \\
\hline None & 1.6 \\
\hline \multicolumn{2}{|l|}{ Delay before diverting } \\
\hline 5-10 min. & 24.7 \\
\hline $10-30 \mathrm{~min}$. & 57.7 \\
\hline 30-60 min. & 14.7 \\
\hline More than $60 \mathrm{~min}$. & 2.4 \\
\hline None & 0.5 \\
\hline
\end{tabular}


Table 4.7 Effect of VMS Message Content (Mail-back Survey Sample)

\begin{tabular}{|c|c|c|c|c|c|c|}
\hline \multirow{3}{*}{$\begin{array}{c}\text { VMS } \\
\text { Message } \\
\text { Type }\end{array}$} & \multirow{3}{*}{ Message Content } & \multicolumn{5}{|c|}{ Relative Willingness to Divert } \\
\hline & & 1 & 2 & 3 & 4 & 5 \\
\hline & & $\%$ & $\%$ & $\%$ & $\%$ & $\%$ \\
\hline 1 & Occurrence of accident only & 20.7 & 17.1 & 33.1 & 18.6 & 10.5 \\
\hline 2 & Location of the accident only & 8.7 & 24.1 & 34.1 & 21.0 & 12.1 \\
\hline 3 & Expected delay only & 5.0 & 8.4 & 32.3 & 36.5 & 17.8 \\
\hline 4 & The best detour strategy only & 5.5 & 21.0 & 21.3 & 31.8 & 20.5 \\
\hline 5 & $\begin{array}{l}\text { Location of the accident and the best detour } \\
\text { strategy }\end{array}$ & 1.3 & 3.7 & 21.0 & 32.0 & 42.0 \\
\hline 6 & $\begin{array}{l}\text { Location of the accident and the expected } \\
\text { delay }\end{array}$ & 1.6 & 3.1 & 14.4 & 35.7 & 45.1 \\
\hline 7 & Expected delay and the best detour strategy & 1.6 & 3.4 & 13.1 & 28.9 & 53.0 \\
\hline 8 & $\begin{array}{l}\text { Location of the accident, expected delay } \\
\text { and the best detour strategy }\end{array}$ & 0.5 & 1.8 & 4.5 & 19.4 & 73.8 \\
\hline
\end{tabular}


Table 4.8 Socioeconomic Characteristics of the Internet-based Survey Sample

\begin{tabular}{llc}
\hline Attribute & Range & Percentage \\
\hline Gender & Male & 73.5 \\
& Female & 26.5 \\
\multirow{4}{*}{ Age Group } & $<20$ & \\
& $20-29$ & 14.7 \\
& $30-39$ & 38.2 \\
& $40-49$ & 29.4 \\
& $50-64$ & 11.8 \\
& $\geq 65$ & 5.9 \\
Education Level & & 0.0 \\
& High School or less & \\
& Some College & 0.0 \\
& College Graduate & 20.6 \\
& Post Graduate & 23.9 \\
& & \\
Persons in Household & 1 & 5.9 \\
& 2 & 55.9 \\
& 3 & 11.8 \\
& $\geq 4$ & 26.4 \\
\hline
\end{tabular}


Table 4.9 Diversion Characteristics of the Internet-based Survey Sample

\begin{tabular}{|c|c|}
\hline Sample Attributes & Frequency $(\%)$ \\
\hline \multicolumn{2}{|l|}{ Familiar with VMS } \\
\hline Yes & 79.4 \\
\hline No & 20.6 \\
\hline \multicolumn{2}{|c|}{ Regular driver on the Borman Expressway } \\
\hline Yes & 97.1 \\
\hline No & 2.9 \\
\hline \multicolumn{2}{|c|}{ Familiarity with alternate routes } \\
\hline Very familiar & 72.7 \\
\hline Familiar & 24.2 \\
\hline Undecided & 0.0 \\
\hline Not familiar & 3.1 \\
\hline Not familiar at all & 0.0 \\
\hline \multicolumn{2}{|c|}{ Average work commute time } \\
\hline 5-10 min. & 2.9 \\
\hline 10-30 min. & 50.1 \\
\hline $30-60 \mathrm{~min}$. & 23.5 \\
\hline More than $60 \mathrm{~min}$. & 23.5 \\
\hline None & 0.0 \\
\hline \multicolumn{2}{|c|}{ Diverting under adverse weather conditions } \\
\hline Yes & 82.4 \\
\hline No & 17.6 \\
\hline \multicolumn{2}{|l|}{ Diverting at night } \\
\hline Yes & 67.6 \\
\hline No & 32.4 \\
\hline \multicolumn{2}{|c|}{$\begin{array}{l}\text { Diverting even when believing that alternate } \\
\text { route would be longer }\end{array}$} \\
\hline Strongly agree & 14.7 \\
\hline Agree & 32.4 \\
\hline Undecided & 29.4 \\
\hline Disagree & 17.6 \\
\hline Strongly disagree & 5.9 \\
\hline \multicolumn{2}{|c|}{ Travel time savings under work-related trip } \\
\hline 5-10 min. & 35.3 \\
\hline 10-30 min. & 52.9 \\
\hline 30-60 min. & 11.7 \\
\hline More than $60 \mathrm{~min}$. & 0.0 \\
\hline None & 0.0 \\
\hline \multicolumn{2}{|c|}{ Travel time savings under personal trip } \\
\hline 5-10 min. & 35.3 \\
\hline 10-30 min. & 41.2 \\
\hline $30-60 \mathrm{~min}$. & 17.6 \\
\hline More than $60 \mathrm{~min}$. & 5.9 \\
\hline None & 0.0 \\
\hline \multicolumn{2}{|l|}{ Delay before diverting } \\
\hline 5-10 min. & 32.3 \\
\hline $10-30 \mathrm{~min}$. & 47.1 \\
\hline 30-60 min. & 20.6 \\
\hline More than $60 \mathrm{~min}$. & 0.0 \\
\hline None & 0.0 \\
\hline
\end{tabular}


Table 4.10 Effect of VMS Message Content (Internet-based Survey Sample)

\begin{tabular}{|c|c|c|c|c|c|c|}
\hline \multirow{3}{*}{$\begin{array}{c}\text { VMS } \\
\text { Message } \\
\text { Type } \\
\end{array}$} & \multirow{3}{*}{ Message Content } & \multicolumn{5}{|c|}{ Relative Willingness to Divert } \\
\hline & & 1 & 2 & 3 & 4 & 5 \\
\hline & & $\%$ & $\%$ & $\%$ & $\%$ & $\%$ \\
\hline 1 & Occurrence of accident only & 26.5 & 17.6 & 29.4 & 17.6 & 8.8 \\
\hline 2 & Location of the accident only & 5.9 & 35.3 & 29.4 & 23.5 & 5.9 \\
\hline 3 & Expected delay only & 2.9 & 5.9 & 38.2 & 44.1 & 8.8 \\
\hline 4 & The best detour strategy only & 2.9 & 20.6 & 29.4 & 41.2 & 5.9 \\
\hline 5 & $\begin{array}{l}\text { Location of the accident and the best detour } \\
\text { strategy }\end{array}$ & 0.0 & 2.9 & 35.3 & 32.4 & 29.4 \\
\hline 6 & $\begin{array}{l}\text { Location of the accident and the expected } \\
\text { delay }\end{array}$ & 2.9 & 2.9 & 14.7 & 41.2 & 38.2 \\
\hline 7 & Expected delay and the best detour strategy & 2.9 & 5.9 & 8.8 & 38.2 & 44.1 \\
\hline 8 & $\begin{array}{l}\text { Location of the accident, expected delay and } \\
\text { the best detour strategy }\end{array}$ & 0.0 & 0.0 & 5.9 & 29.4 & 64.7 \\
\hline
\end{tabular}


Table 4.11 Explanatory Variables Included in the Logit Models

\begin{tabular}{|c|c|}
\hline Explanatory Variable & Mnemonics \\
\hline Alternative specific constant & ONE \\
\hline $\begin{array}{l}\text { Sex } \\
=1, \text { if male } \\
=0, \text { if female }\end{array}$ & SEX \\
\hline $\begin{array}{l}\text { Age group } \\
=1, \text { if age } \geq 40 \text { years } \\
=0, \text { if age }<40 \text { years }\end{array}$ & AGE \\
\hline $\begin{array}{l}\text { Level of education } \\
=1, \text { if education } \leq \text { some college } \\
=0, \text { if education } \geq \text { college }\end{array}$ & EDU \\
\hline $\begin{array}{l}\text { Dummy variable for truck drivers } \\
=1, \text { if respondent is a truck driver } \\
=0, \text { otherwise }\end{array}$ & TRUCK \\
\hline $\begin{array}{l}\text { Regular driver in the Borman Expressway region } \\
=1, \text { if Yes } \\
=0, \text { if No }\end{array}$ & DRIV \\
\hline $\begin{array}{l}\text { Familiarity with alternate routes } \\
=1, \text { if familiar } \\
=0, \text { if not familiar }\end{array}$ & FAM \\
\hline $\begin{array}{l}\text { Average commuting travel time to work } \\
=1, \text { if travel time } \geq 30 \text { minutes } \\
=0, \text { if travel time }<30 \text { minutes }\end{array}$ & COMM \\
\hline $\begin{array}{l}\text { Trust in information provided } \\
=1, \text { if high } \\
=0, \text { otherwise }\end{array}$ & TRUST \\
\hline $\begin{array}{l}\text { Amount of delay convincing a driver to divert } \\
=1, \text { if delay } \geq 10 \text { minutes } \\
=0, \text { if delay }<10 \text { minutes }\end{array}$ & DELAY \\
\hline $\begin{array}{l}\text { Dummy variables corresponding to each VMS } \\
\text { message type, } \mathrm{k}=2 \text { to } 8\end{array}$ & $\mathrm{VMS}_{\mathrm{k}}$ \\
\hline
\end{tabular}


Table 4.12 Logit Models for Driver Response Under VMS Using the On-site Survey Data

\begin{tabular}{|c|c|c|c|c|}
\hline \multirow{3}{*}{ Variable } & \multicolumn{4}{|c|}{ Model } \\
\hline & General & Truck Drivers & Non-truck Drivers & Interaction \\
\hline & Coeff. (t-ratio) & Coeff. (t-ratio) & Coeff. (t-ratio) & Coeff. (t-ratio) \\
\hline ONE & $-1.942(-10.45)$ & $-1.500(-4.50)$ & $-2.586(-10.52)$ & $-2.472(-12.64)$ \\
\hline SEX & $0.433(3.26)$ & $0.640(1.62)$ & $0.416(2.45)$ & $0.266(1.91)$ \\
\hline AGE & $-0.458(-4.17)$ & & $-0.238(-1.53)$ & $-0.422(-3.77)$ \\
\hline EDU & $-0.308(-2.74)$ & & & \\
\hline TRUCK & & & & $-0.371(-1.29)$ \\
\hline DRIV & 0.207 (1.87) & $0.454(2.50)$ & & \\
\hline FAM & & $0.662(3.22)$ & & \\
\hline TRUST & $0.666(5.84)$ & $0.516(3.11)$ & $0.916(5.61)$ & $0.924(5.82)$ \\
\hline $\mathrm{VMS}_{3}$ & $0.656(3.83)$ & & $1.154(4.48)$ & $1.051(4.48)$ \\
\hline $\mathrm{VMS}_{4}$ & $0.886(5.22)$ & $0.750(3.39)$ & $1.046(4.03)$ & $0.937(5.35)$ \\
\hline $\mathrm{VMS}_{5}$ & $2.128(11.78)$ & $1.588(6.52)$ & $2.671(10.10)$ & $2.357(10.68)$ \\
\hline $\mathrm{VMS}_{6}$ & $2.535(13.16)$ & $2.312(8.00)$ & $2.864(10.60)$ & $2.683(13.34)$ \\
\hline $\mathrm{VMS}_{7}$ & $2.775(13.73)$ & $1.940(7.40)$ & $3.577(11.78)$ & $3.442(12.35)$ \\
\hline $\mathrm{VMS}_{8}$ & $3.593(14.27)$ & $3.163(8.19)$ & $4.057(11.92)$ & $3.776(14.51)$ \\
\hline DRIV*TRUCK & & & & $0.549(2.92)$ \\
\hline FAM*TRUCK & & & & $0.713(3.35)$ \\
\hline TRUST*TRUCK & & & & $-0.525(-2.27)$ \\
\hline $\mathrm{VMS}_{3} * \mathrm{TRUCK}$ & & & & $-0.712(-2.31)$ \\
\hline $\mathrm{VMS}_{5}{ }^{*} \mathrm{TRUCK}$ & & & & $-0.762(-2.33)$ \\
\hline $\mathrm{VMS}_{7} * \mathrm{TRUCK}$ & & & & $-1.279(-3.45)$ \\
\hline Sample size & 1984 & 928 & 1056 & 1984 \\
\hline $\mathrm{L}(0)^{1}$ & -1375.20 & -643.24 & -731.96 & -1375.20 \\
\hline $\mathrm{L}(\hat{\boldsymbol{\beta}})$ & -1037.75 & -499.73 & -519.34 & -1009.77 \\
\hline$\rho^{2}$ & 0.245 & 0.223 & 0.290 & 0.266 \\
\hline
\end{tabular}


Table 4.13 Logit Model for Driver Response Under VMS Using the Mail-back Survey Data

\begin{tabular}{lc}
\hline Variable & Coeff. (t-ratio) \\
\hline ONE & $-1.085(-6.01)$ \\
EDU & $-0.148(-1.69)$ \\
DRIV & $0.446(2.62)$ \\
FAM & $0.834(5.34)$ \\
COMM & $0.138(1.53)$ \\
TRUST & $0.298(3.33)$ \\
DELAY & $0.398(3.46)$ \\
VMS $_{2}$ & $0.190(1.39)$ \\
VMS $_{3}$ & $1.100(7.08)$ \\
VMS $_{4}$ & $1.013(6.52)$ \\
VMS $_{5}$ & $2.004(12.11)$ \\
VMS $_{6}$ & $2.408(13.72)$ \\
VMS $_{7}$ & $2.479(13.96)$ \\
VMS $_{8}$ & $3.604(15.32)$ \\
\hline Sample size $=3048$ \\
L $(0)=-2018.98, \mathrm{~L}(\boldsymbol{\beta})=-1583.66$ \\
$\rho^{2}=0.216$ &
\end{tabular}


Table 4.14 Logit Model for Driver Response Under VMS Using the Internet-based Survey Data

\begin{tabular}{lc}
\hline Variable & Coeff. (t-ratio) \\
\hline ONE & $-2.033(-3.51)$ \\
SEX & $1.023(2.73)$ \\
AGE & $-1.608(-3.66)$ \\
EDU & $-1.029(-2.55)$ \\
COMM & $1.509(3.81)$ \\
DELAY & $1.048(2.94)$ \\
VMS $_{3}$ & $1.386(2.74)$ \\
VMS $_{4}$ & $1.075(2.14)$ \\
VMS $_{5}$ & $1.860(3.58)$ \\
VMS $_{6}$ & $2.970(5.02)$ \\
VMS $_{7}$ & $3.205(5.21)$ \\
VMS $_{8}$ & $4.638(5.36)$ \\
Sample size $=272$ \\
L $(0)=-122.81, \mathrm{~L}(\boldsymbol{\beta})=-183.91$ \\
$\rho^{2}=0.332$ &
\end{tabular}


Table 4.15 Logit Model for Driver Response Under VMS Using the Combined Survey (On-site, Mail-back, and Internet-based) Data

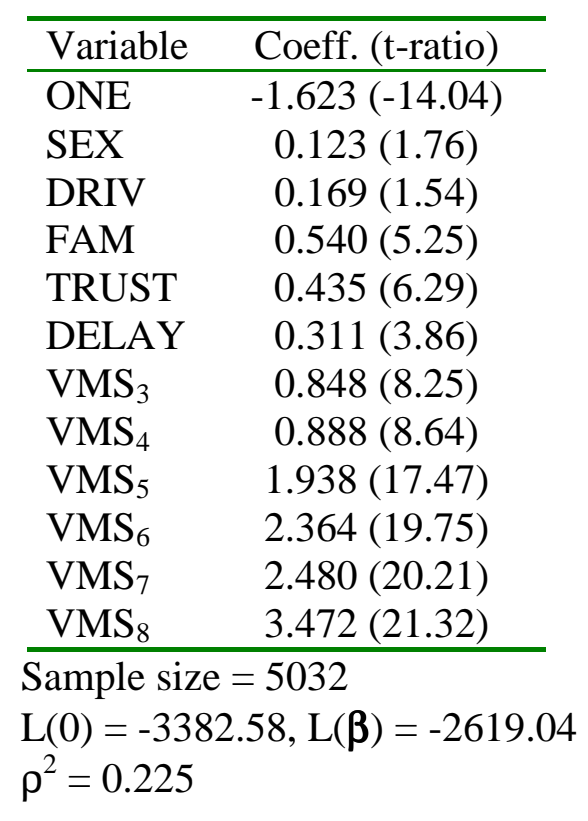




\section{DETERMINATION OF OPTIMAL VMS MESSAGES}

A key objective of the study is to develop a heuristic procedure for optimizing network performance using VMS-based messages that would be both general in its scope of application and computationally efficient from a real-time deployment perspective. In order to accomplish this the heuristic procedure needs to possess certain properties. First, it has to be simple so that its execution can be kept within bounds imposed by realtime operational constraints. Second, it should not impose network specific restrictions on the algorithmic logic so as to ensure transferability. Third, it has to be robust so that fluctuations in demand and supply can be accounted for. A rule-based approach was adopted to address these issues.

Computational efficiency can be obtained if the VMS procedure does not introduce any expensive computations that need to be done in addition to those in the traditional on-line DTA solution procedure discussed in Chapter 2. The DTA procedure computes the optimal path assignment proportions for the user classes in the traffic stream. The VMS heuristic uses these proportions to determine the messages to be displayed consistent with driver VMS response attitudes. Two standard assignment objectives are used to determine the optimal VMS messages. They are: user equilibrium (UE) and 
system optimal (SO). While UE represents a reasonable proxy for actual driver behavior, the SO objective provides a benchmark for the best possible system performance. Hence, the SO objective based VMS solution is the desired one from the traffic controller perspective.

To ensure that the scope of the heuristic is general, it does not make network specific assumptions. It uses the driver response and incident clearance prediction models for that network. These models serve as inputs which can be plugged into the heuristic to determine the VMS messages under an incident. The heuristic can hence be ported to any network for which driver response models and incident clearance prediction models are available. An advantage of such an approach is that it obviates the need for different VMS heuristics for different networks, unlike many existing models which are network specific.

The solution robustness issue is addressed by using a robust hybrid methodology [5] to compute the optimal DTA path assignment proportions. It combines off-line and on-line procedures that account for stochasticity in demand and supply conditions. The VMS heuristic can use these proportions to determine the messages to be displayed. Hence, the robustness of the VMS heuristic depends on the robustness of the procedure employed to determine the optimal VMS path assignment proportions.

\subsection{Problem Description}

A key factor motivating the VMS-based traffic management problem is that the current market penetration of in-vehicle navigation systems (IVNS) is considerably less than that of VMS. VMS are being extensively deployed in the US to disseminate 
congestion information, workzone information, and lane closure notification, as well as for parking and route guidance.

Route guidance through VMS, is however, a recent functional application. It has been used to address congestion problems for specific network topologies. This study aims to develop a general framework which uses VMS to optimize traffic system performance.

\subsubsection{Problem Statement}

Given a traffic network $\mathrm{G}(\mathrm{N}, \mathrm{A})$ with $\mathrm{N}$ nodes, A arcs, user class fractions, variable message signs at pre-specified locations, a VMS driver diversion response model, and an incident clearance time prediction model, the traffic system controller seeks to determine the time-dependent VMS messages to be displayed during the horizon of interest (typically under incidents) that address some system-wide objectives and are consistent with driver VMS response behavior. Implicit in the VMS problem is the usage of message content as a control variable to achieve desired diversion rates. Practically, the problem consists of determining: (i) the VMS to be activated for message display, (ii) the messages to be displayed, and (iii) the frequency at which messages should be updated, so that unequipped drivers diverting based on their VMS diversion response attitudes satisfy some system-wide objectives of the traffic controller. The user class fractions can be based on unequipped and equipped drivers. However, equipped drivers may further be categorized into classes such as user equilibrium (UE) objective drivers and system optimal (SO) objective drivers. 
A key difference of the proposed problem from previously addressed VMS problems is the explicit consideration of driver diversion response behavior while satisfying system controller objectives. Hence, the response attitudes of drivers to the displayed VMS is accounted for.

\subsubsection{Issues}

Issue 1: Messages to be displayed

This is the main objective of the VMS problem. The issue of determining the time-dependent messages to be displayed entails the consideration of the following subissues:

(i) The type of message to be displayed. Based on the type of information disseminated, VMS messages can be broadly classified as informative messages, advisory (descriptive) messages, and route guidance (prescriptive) messages. As discussed in Chapter 4, different message types (see Table 4.1) can be used to induce different diversion rates.

(ii) The content of the message to be displayed. This involves the consideration of the actual semantics of the message displayed in terms of the particular choice of parameters (qualitative and/or quantitative) that characterize the system state and influence driver response. Hence, the message content (see Table 4.1) is used as a control variable to enhance the traffic system performance. The driver response is determined using the SP survey discussed in Chapter 4. Issue 2: VMS to be activated

Given the network topology and the location of the permanent VMS, messages activated at a specific set of locations may have the most beneficial influence on traffic 
flows vis-a-vis optimizing system performance than at other locations for the given traffic conditions. The current study aims to identify these locations and the messages to be displayed on the VMS at these locations. There may be VMS that do not require activation under a given incident scenario. In such a case, it is important from a computational standpoint that unnecessary combinations are not considered so as to satisfy the real-time constraints imposed by the problem.

Issue 3: Placement of portable VMS

Issue 2 involves the determination of appropriate message display locations to optimize system performance. Based on the specific traffic conditions, there may be some paths requiring significant amounts of traffic diversion, but lack a VMS. These paths are potential candidates for deployment of portable VMS. If certain pre-determined thresholds for traffic diversion are exceeded at any location consistently over several incident scenarios, a case can be made for installing a permanent VMS at that location.

Issue 4: Update frequency

It is important to determine how frequently the messages will have to be updated, for two reasons. First, if the messages are updated too quickly they may not have the desired effect in terms of the desired diversion rates, and there may be the further risk of drivers perceiving the messages as unreliable because of the frequent changes. Second, the update frequency determines how often the optimal VMS messages are to be determined, thereby circumventing periodic computations. 


\subsubsection{Assumptions}

The proposed VMS heuristic is based on certain assumptions which control the nature of the solution (path assignment proportions) and consequently the messages to be displayed on the VMS. These assumptions are stated below:

- The VMS heuristic is deployed only under incident conditions.

- Driver response models for the messages displayed on the VMS are assumed to be available (see Chapter 4).

- An incident clearance prediction model is assumed to be available (see Chapter 3).

- VMS messages are assumed to affect only unequipped users in the network. It is reasonable to assume that equipped users receiving personalized information will ignore VMS messages due to their generic nature.

\subsection{Solution Methodology}

\subsubsection{VMS-Based Optimal Diversion Rates Heuristic}

The proposed VMS control heuristic addresses the problem by determining optimal diversion rates for unequipped drivers under current network conditions. The primary objective of the VMS control heuristic is to obtain diversion rates and consequently new path assignment proportions for unequipped drivers whose predetermined paths (historical paths) include the incident link. These drivers, in the absence of any information, follow their fixed pre-determined paths. However, if a VMS is present upstream of the incident link it can be used to divert them from these paths by 
providing routing information that aids incident management. This ensures that drivers do not queue upstream of the incident link leading to increased system delays.

The VMS control heuristic ensures that the VMS are inactive when there is no incident/congestion and after the effects of an incident/congestion on the network have dissipated. The control heuristic uses the driver diversion response model to determine the messages to be displayed from the diversion rates obtained. The display locations are determined by comparing diversion rates with threshold activation criteria. Messages are updated based on traffic data feedback. The VMS control heuristic consists of three subalgorithms that follow a sequential logic to determine: (i) the VMS that should be activated, (ii) the messages to be displayed on the active VMS, and (iii) the frequency with which the VMS messages should be updated. The sub-algorithms are as follows:

\subsubsection{The Activation Algorithm}

The Activation algorithm determines the VMS to be activated for message display (by the Message Display algorithm) through a set of heuristic rules. These rules activate only those VMS for which the required diversion rates to improve system performance exceed a pre-specified threshold. This implicitly ensures that the sensitivity of the network performance vis-à-vis the diversion achieved by the identified VMS is significant. It eliminates the need to activate VMS which do not significantly influence system performance. This aspect is computationally attractive from an operational standpoint.

The algorithm lists all origin-destination (O-D) pairs in the network as candidates for determining incident-affected paths. From this set the $\mathrm{K}$ most used paths (in terms of 
path flows) between each O-D pair that include the incident link are identified. Any VMS on these paths are activated if they satisfy either of the following activation criteria: (i) VMS is within R minutes of incident link, or (ii) VMS is within Y miles of the incident, where $\mathrm{R}$ and $\mathrm{Y}$ are pre-determined parameters specific to that network.

The $\mathrm{K}$ most used paths that include the incident link are obtained using the immediate past data on the network state. $\mathrm{R}$ is determined from the time-dependent path travel times and is a more robust filter criteria than $\mathrm{Y}$ because it better reflects the ambient traffic conditions. It could, for example, be a percentage of the path travel time from the origin node to the upstream node of the incident-affected link, or a measure based on the predicted incident clearance time. It can be time-dependent to reflect improvements in the network performance due to the VMS strategy adopted in previous intervals, and hence enhances the efficiency of the VMS control heuristic. While the use of $\mathrm{Y}$ is less meaningful in congested situations, it can be a useful threshold in the absence of time-dependent network data. Besides, it is useful when addressing incidents involving hazardous material spills which require the quarantining of a region.

\subsubsection{The Message Display Algorithm (MDA)}

The Message Display Algorithm, illustrated in Figure 5.1, determines the optimal messages to be displayed on the VMS selected by the Activation algorithm using one of two system controller objectives, user equilibrium (UE) or system optimal (SO) flow patterns. A multiple user classes deterministic DTA algorithm [3] is used to determine the optimal path assignment proportions under the incident (case 1), based on the objective (SO or UE), for computing the desired diversion rates. The deterministic DTA model 
calculates the optimal path assignment proportions in a network with multiple user classes over a planning horizon of interest. It takes as input deterministic O-D desires and an initial path set for all drivers and determines path assignment proportions that optimize system performance. In this case, the unequipped drivers are assumed to be UE (SO) users for the UE (SO) objective. The optimal assignments are also computed using the actual user class fractions (case 2). The optimal path assignment proportions from the two scenarios are used to determine the messages to be displayed on the VMS. This is done by comparing the path assignment proportions from case 2 with the desired path assignment proportions from case 1 . If the proportions are larger in case 2 compared to case 1 for the incident-affected VMS paths, unequipped users could be induced to switch from those paths through appropriate VMS messages. Hence, the desired objective is to seek the network flow pattern under case 1 . The percentage diversion of unequipped drivers from the VMS links represents the desired diversion rates. However, a single VMS may lie on paths requiring different diversion rates. Since only one message can be displayed on the VMS for all such paths, a combined measure of these diversion rates has to be considered for operational purposes. From the limited experiments conducted in this study, an average of these diversion rates seems to represent a good proxy for the desired diversion rate. The diversion rate from the VMS driver diversion response model that is closest to the desired diversion rate for a particular VMS is used to determine the message to be displayed. Figure 5.1 illustrates the algorithm for the UE objective. The SO objective solution can be obtained by substituting UE by SO in the figure. Here, T denotes the length of the planning horizon. 


\subsubsection{The Update Frequency Algorithm}

The displayed VMS messages need to be updated over time to reflect changes in the incident situation and/or traffic flow conditions. For example, progress in the incident clearance may enable increased capacity on the incident link leading to an increased ability to route traffic through the incident area. Similarly, improved traffic conditions in the vicinity of the incident due to prior VMS messages may require the updating of the messages displayed. The Update Frequency algorithm determines when such updates should occur, that is when to invoke the Message Display algorithm. It does so by monitoring at regular intervals the incident clearance situation and the flow conditions in the incident vicinity. The length of the monitoring interval depends on the specific network and incident situation. Hence, the Update Frequency algorithm can aid the efficiency of the VMS control heuristic and its effectiveness vis-à-vis system performance. The logic of the Update Frequency algorithm is as follows:

Incident Link: If the incident link capacity in the monitoring interval $\tau$ is $\alpha \%$ different from that of interval $(\tau-1)$, where $\alpha$ is a pre-set time-dependent threshold, the MDA is invoked.

Ambient Traffic Conditions: If the incident link conditions do not warrant an update, the ambient traffic conditions in its vicinity are analyzed. This is done by computing the updated instantaneous path travel times on the $\mathrm{K}$ most used paths from each origin node to the incident link upstream node. If the difference in the path travel times for $\beta$ number of these paths in two successive monitoring intervals exceeds $\gamma \%$, MDA is invoked. Here, $\beta$ and $\gamma$ are pre-specified thresholds. 
If neither of these two update criteria trigger an update, the current messages are retained. Incident clearance time prediction models (see Chapter 3) are used to estimate the remaining incident clearance time and project when the messages are likely to be deactivated.

\section{$\underline{5.3 \quad \text { VMS Control Heuristic Implementation }}$}

The proposed VMS control heuristic is implemented using a hybrid framework [5] consisting of off-line and on-line components. The off-line component addresses the computationally intensive components and the on-line component uses an efficient rolling horizon implementation that circumvents future state predictions. The rolling horizon implementation is ideal from the perspective of the on-line deployment [3] because of the computational time savings obtained by using a truncated planning horizon.

Off-line component: The computationally intensive off-line component determines the time-dependent path assignment proportions using a deterministic DTA algorithm for several probable incident scenarios and a mean O-D matrix. These proportions are stored for use by the on-line component to determine the optimal diversion rates in a computationally efficient manner.

On-line component: Figure 5.2 illustrates the rolling horizon implementation of the VMS control heuristic. It is a stage-based approach illustrating the on-line nature of the VMS control heuristic. A stage is a truncated portion of the planning horizon, implying lesser computational effort. The planning horizon is divided into several stages. If an incident and/or high congestion is detected in the current stage the VMS control heuristic described earlier is executed to determine optimal time-dependent path assignment 
proportions and messages to be displayed in the next stage. In the absence of incidents and/or high congestion the deterministic DTA model is used to determine the optimal path assignment proportions. The current stage is incremented and the messages determined in the previous stage are implemented for a roll period, which is a subinterval of a stage. The network data collected from detectors is used to repeat this process in the next stage.

Figure 5.3 illustrates a typical cycle of the VMS control heuristic using the rolling horizon framework. The flow of logic in the figure is for the stage i in which the incident is first detected. It is used to determine the messages to be implemented in stage $\mathrm{i}+1$. The inputs are the predicted O-D desires of drivers departing in this stage and the historical paths for the unequipped drivers. The VMS messages are assumed to influence only the unequipped drivers. The Activation algorithm determines the VMS locations for activation. The Message Display Algorithm determines the message to be displayed by mapping diversion rates onto actual messages by mapping diversion rates onto actual messages by through a driver diversion response model.

Figure 5.4 illustrates the execution of the VMS control heuristic within any stage subsequent to the stage in which the incident is detected. The Update Frequency algorithm is executed for each monitoring interval and is used for updating messages within the current stage using the update criteria stated earlier. The monitoring interval is a sub-interval of the current roll period. If neither of the update criteria are satisfied the messages remain unchanged.

The control heuristic is repeated until all the VMS are deactivated implying that the adverse effects of the incident on the network have dissipated. A computationally 
attractive feature of this approach is that the MDA is activated only when deemed necessary by the Update Frequency algorithm. Additionally the parameters in the Update Frequency algorithm can be adjusted to vary the frequency of MDA activation to suit the resources of the traffic controller. 


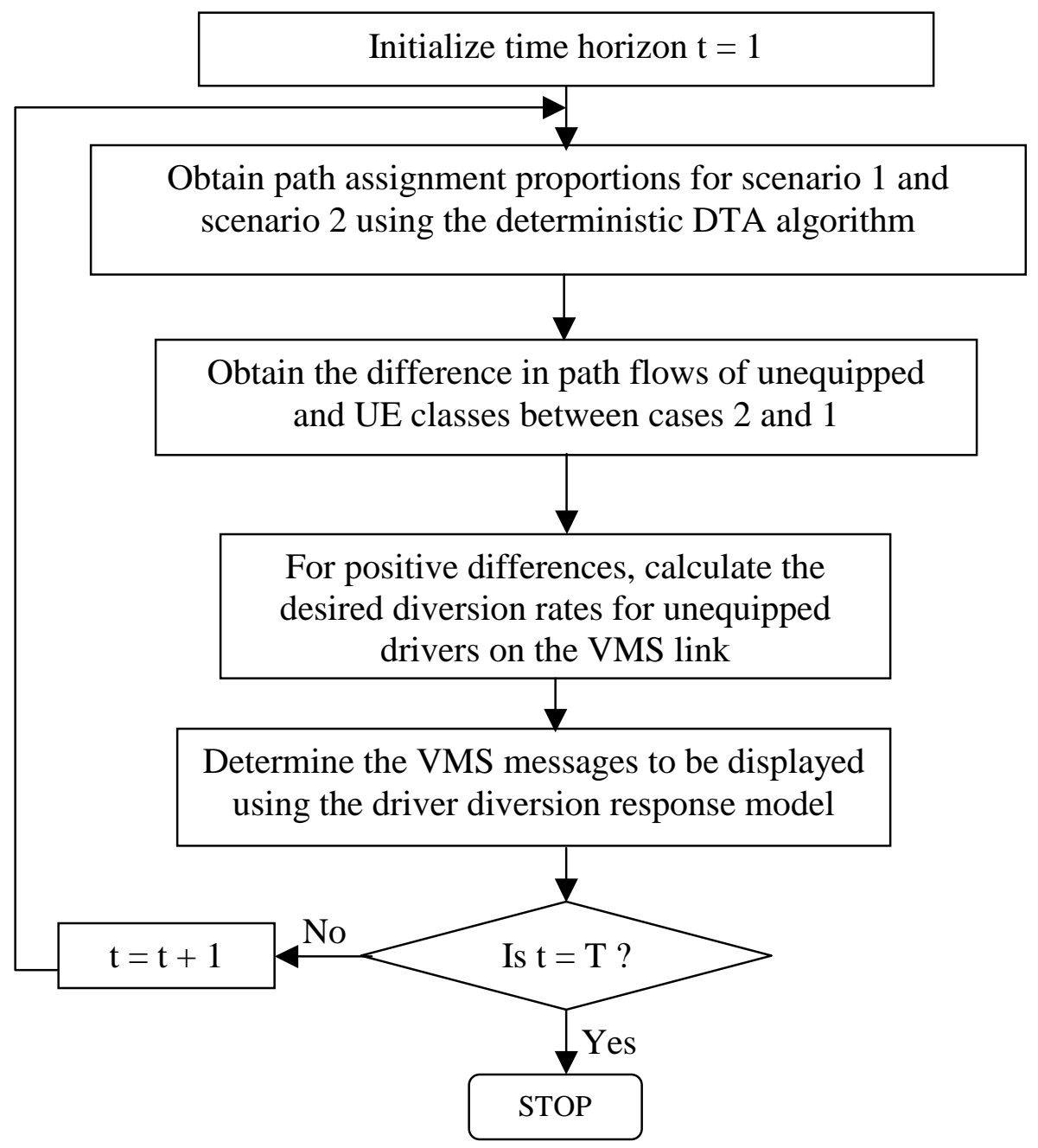

Figure 5.1 Message Display Algorithm 


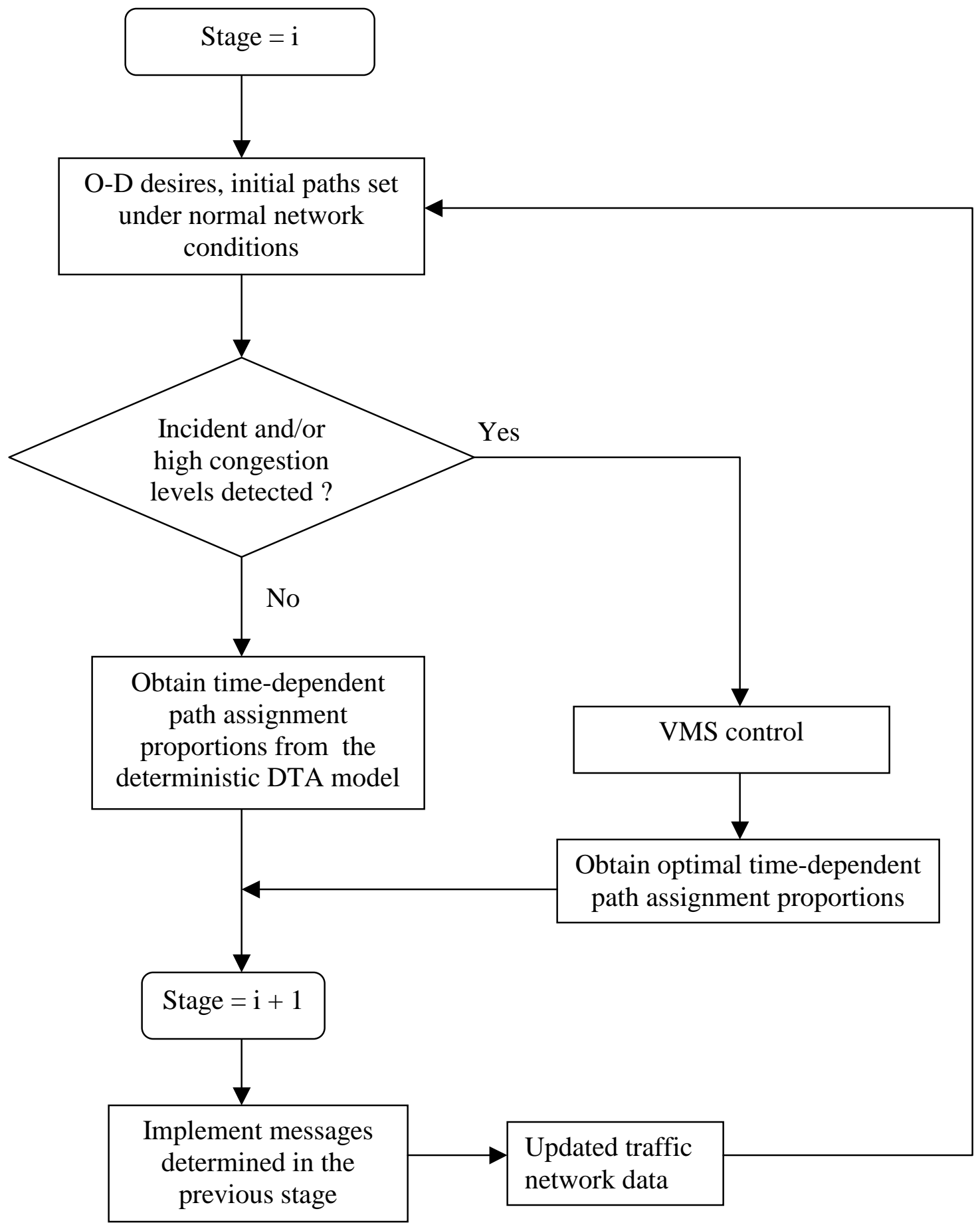

Figure 5.2 Rolling Horizon Implementation 




Figure 5.3 The Rolling Horizon Implementation of the VMS Control Heuristic in the Stage that the Incident is First Detected (i) 


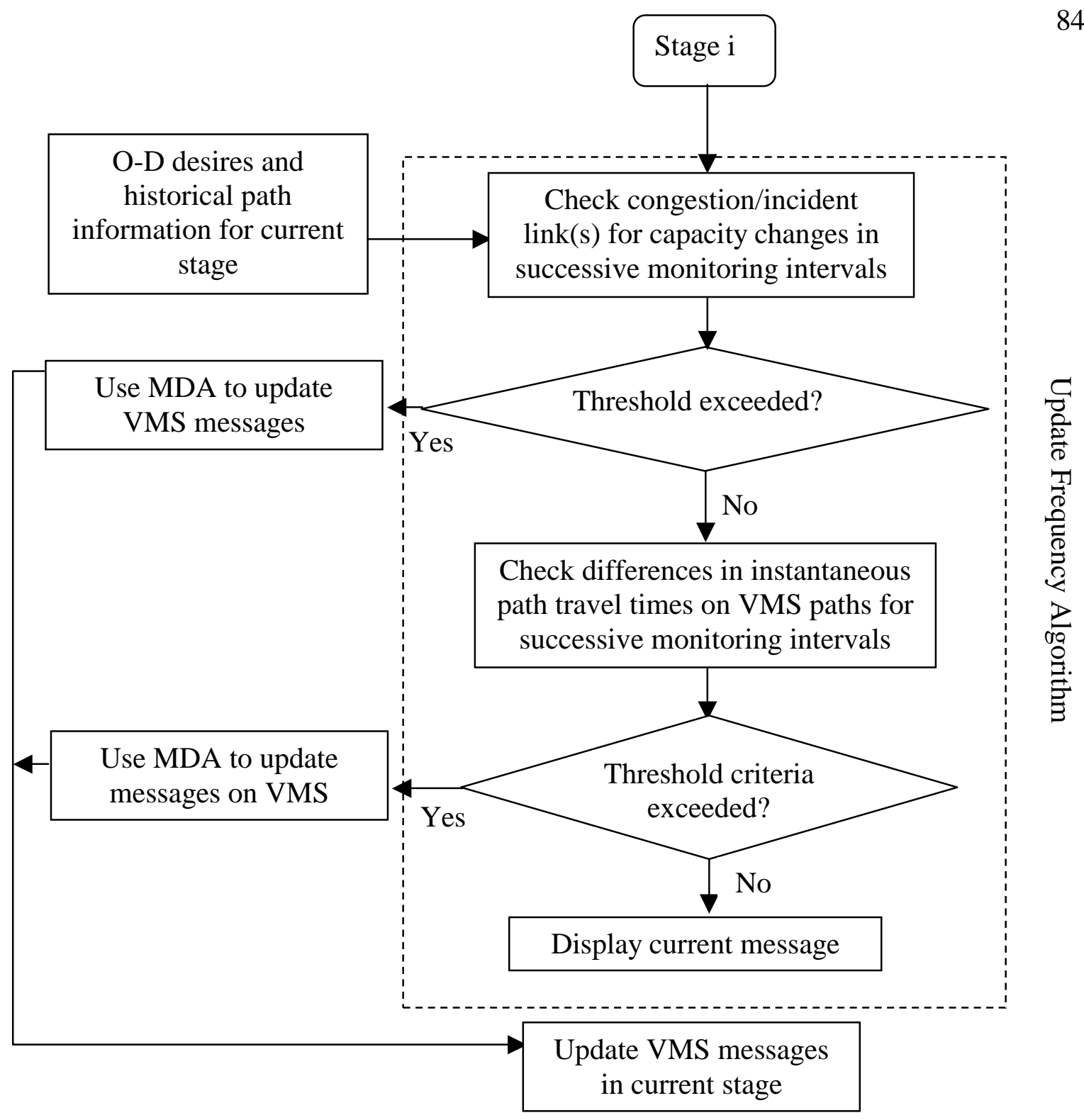

Figure 5.4 The Rolling Horizon Implementation of the VMS Control Heuristic in Stages Following the Detection of the Incident 


\section{CONCLUSIONS}

This study focuses on the development of an on-line route advisory and guidance framework using VMS. This chapter provides some concluding remarks and recommendations.

\subsection{General Comments}

A solution methodology for optimizing network performance using VMS message content as the primary control variable was developed. The key difference of the proposed methodology from previous VMS-based incident management approaches is its consistency with driver VMS response behavior. Given driver response to VMS information and incident duration prediction models, the control strategy is capable of determining the VMS signs to be activated, the VMS message to be displayed, and the message update frequency. This makes the control process more realistic from the perspective of users and is especially useful under on-line route-guidance where the realism of the adopted strategy is critical to system performance. An important characteristic of this methodology is that it is general in its scope of application. It can be ported to any network for which drivers' VMS response models and incident clearance time prediction models are available. The framework is general because it does not make any network specific assumption beyond taking into consideration the drivers' response 
model for user in that region and incident clearance time prediction models. The solution methodology is also computationally efficient from a real-time deployment perspective.

Different SP survey administration methods were adopted in this study: (i) onsite, (ii) mail-back survey, and (iii) Internet-based survey. The multiple administration method was adopted to more effectively sample the target population. The on-site survey targeted commuters, infrequent Borman travelers, and truck drivers on the Borman Expressway. The mail-back and Internet-based surveys were used to target residents and businesses in the Borman region. Hence, the combined survey sample is representative of the different groups of individuals using the Borman Expressway. Although the Internet-based survey offered some advantages, the response rate was very low. However, as Internet usage becomes more commonplace, the various advantages of Internet-based surveys such as greater target audience access, greater data automation, etc., will increase their attractiveness vis-à-vis driver behavior sampling. Since the online VMS route advisory and guidance framework can be ported to any traffic network, Internet-based surveys represent a long-term cost-effective approach for INDOT for driver behavior sampling in other traffic regions in the state.

The commonly used SP approach has a number of well-understood limitations. First, the SP responses may not satisfactorily reflect actual behavior. Second, in the context of VMS driver response, SP surveys can be lengthy (to address the multiple actual scenarios possible). However, the current sparsity in VMS response field data suggests SP methodology as an effective tool to address driver behavior under a variety 
of scenarios. The SP study provides some important insights on VMS survey design and drivers attitudes for on-line traffic operations.

An important contribution of this work is the insights it provides for diversion behavior under the influence of different VMS message contents. The strong correlation between VMS message types and driver response suggests message content as an important control variable for improving system performance without compromising the integrity of the information provided. Significant differences were found in the attitudes of truck and non-truck drivers. This is important for the use of VMS-based information systems to influence network performance in commercial corridors such as the Borman Expressway region where trucks represent a significant percentage of the traffic. The use of a Likert scale in the SP survey vis-à-vis VMS message content enables a finer resolution in understanding the differences between driver response to various message types. A shortcoming of using generic variables is illustrated by the perceived relative values of expected delay and location. While expected delays are perceivable in terms of magnitude without the need for specific scenarios in SP surveys, the value of location is perceivable only in actual situations or specifically constructed SP scenarios for a particular traffic network. Hence, the incident location, in a generic sense, was not found to be significant in this study, though it is in the real world.

Data from the Hoosier Helper logs was used to update existing incident clearance time prediction models. The models estimated were developed using multi-period data, which leads to a more robust prediction of incident clearance time. Variables describing incident severity, the lateral location of the incident, and weather conditions during the 
clean-up operation have significant explanatory power. More refined models in terms of weather data were developed, compared to existing models. Also, the updated models include variables to reflect incident severity. Accurate prediction of incident duration is critical in the context of ATIS because it can aid user confidence vis-à-vis traffic information provision.

\subsection{Recommendations}

As stated in Chapter 4, RP and SP are the two basic approaches of data collection used to model route choice behavior. Most studies in this area tend to rely on SP methods. This is because of the current lack of adequate field data on driver behavior under different VMS messages. However, after the Borman Expressway VMS-based information system is operational, the system can be used to collect field data to estimate diversion prediction models under a specific VMS message type.

The current SP diversion prediction models are static. In other words, they do not take into account situational factors (e.g. current network conditions, current weather conditions, time of day) that may change with time. They capture the effect of only static variables (such as socioeconomic variables) on the propensity to divert. They may at best form part of a larger framework of models that incorporate dynamic variables from actual field data. In addition, an "after" study, which represents driver surveys after drivers have sufficient experience the Borman VMS system, will aid in further calibrating the VMS driver response models developed in this study. They can be used to reflect changing driver response attitudes based on their experience with the VMS-based information. This is important because driver attitudes can change significantly based on 
the perceived value of the information provided. Therefore, field tests and "after" surveys represent should be conducted in the future.

\subsection{Future Work}

Future work will focus on extensive testing of different incident scenarios, congestion levels, path assignment strategies, and user class fractions on the Borman network to obtain insights on the performance and robustness of the VMS heuristic. Experiments will be conducted on other networks to analyze the scope and generality of the procedure. Based on the results from the experiments, recommendations will be made for the on-line deployment of the VMS heuristic as part of an ATMS framework to automate the determination of the optimal VMS messages. 


\section{LIST OF REFERENCES}

[1] FHWA (1998), "Intelligent Transportation Systems", Vision Folder, Publication No. FHWA-JPO-98-024, Washington, DC.

[2] Hughes Transportation Management Systems (1996), "Advanced Traffic Management System Phase I Final Report", a report submitted to Indiana Department of Transportation, May 1996.

[3] Peeta S. (1994). System Optimal Dynamic Traffic Assignment In Congested Networks With Advance Traveler Information Systems. PhD Dissertation, The University of Texas at Austin.

[4] Peeta, S. and Mahmassani, H. S. (1995). "System Optimal and User Equilibrium Time-Dependent Traffic Assignment in Congested Networks", Annals of Operations Research, 60, pp. 81-113.

[5] Peeta S. and Zhou, C. (1999). "A Hybrid Framework for Robust On-line Route Guidance", submitted for publication in Transportation Research Part C.

[6] Benson G. B. (1996). "Motorist Attitudes About Content of Variable Message Signs", Transportation Research Record 1550, TRB, National Research Council, Washington, D.C., pp. 48-57.

[7] Abbas M., McCoy P. (1999). "Optimizing Variable Message Sign Locations on Freeways Using Genetic Algorithms", Paper Presented at the $78^{\text {th }}$ Annual Meeting of Transportation Research Board, Washington, D.C.

[8] Mammar S., Messmer A.,Jensen P., Papageorgiou, M., Haj-Salem H., and Jensen, L. (1996). "Automatic Control of Variable Message Signs in Aalborg", Transportation Research, Part C, Vol. 4, No. 3, pp. 131-150.

[9] Yim Y. and Ygnace, J. L. (1996). "Link Flow Evaluation Using Loop Detector Data: Traveler Response to Variable Message Signs", Transportation Research Record 1550, Washington, D.C., pp. 58-64. 
[10] Chang, G.L., Junchaya, T., and Santiago, A.J. (1994 ). “A Real-Time Network Traffic Simulation Model for ATMS Applications: Part II - Massively Parallel Model”, IVHS Journal, 1(3), pp. 243-259.

[11] Peeta, S., Pasupathy, R., Gedela, S., Zhang, P., and Yuj, J. W., (2000). "A Beowulf Supercomputing Cluster for Real-Time Control of Traffic Systems", to be submitted to Computer-Aided Civil And Infrastructure Engineering; Invited paper for a special issue on "High Performance Computing".

[12] Bonsall P.W. (1995). QUO VADIS V2042 - Report of the findings on driver probable reaction to VMS. Deliverable No.4, Work-package No. 2. Commission of the European Communities $R \& D$ program: Telematics Systems in the area of Transport, DRIVE II.

[13] Madanat, S. and Feroze, A. (1997), "Prediction Models for Incident Clearance Time for Borman Expressway", Joint Transportation Research Program, FHWA/IN/JHRP-96/10, Purdue University, West Lafayette, IN, 1997.

[14] Grenzeback, L. R. and Woodle, C. E. (1992), "The True Costs of Highway Congestion”, ITE Journal, Vol. 62, No. 3, pp.6-10.

[15] Greene, W. H. (1998), LIMDEP Version 7.0 User's Manual, Econometric Software, Inc.

[16] Madanat, S. M., Yang, C. Y., and Yen, Y. M. (1995), “Analysis of Stated Route Diversion Intentions Under Advanced Traveler Information Systems Using Latent Variable Modeling", Transportation Research Record 1485, TRB, National Research Council, Washington, D.C., pp. 10-17.

[17] Polydoropoulou, A., Ben-Akiva, M., Khattak, A., and Lauprete G. (1996), "Modeling Revealed and Stated En-Route Travel Response to Advanced Traveler Information Systems", Transportation Research Record 1537, TRB, National Research Council, Washington, D.C., pp. 38-45.

[18] Wardman, M., Bonsall, P. W., and Shires, J. D. (1997), "Driver Responses to Variable Message Signs: A Stated Preference Investigation", Transportation Research, Part C, Vol. 5, No. 6, pp. 389-405.

[19] Pal, R. (1998), "Investigation on Latent Factors Affecting Route Diversion Intentions", Journal of Transportation Engineering, Vol. 124, No. 4, American Society of Civil Engineers, pp. 362-367.

[20] Khattak, A. J., Schofer, J. L., and Koppelman, F. S. (1993), “Commuters' Enroute Diversion and Return Decisions: Analysis and Implications for Advanced Traveler 
Information Systems”, Transportation Research, Part A, Vol. 27A, No. 2, pp. 101111.

[21] Khattak, A., Kanafani, A., and Le Coteller, E. (1994), "Stated and Reported Route Diversion Behavior: Implications of Benefits of Advanced Traveler Information System", Transportation Research Record 1464, TRB, National Research Council, Washington, D.C., pp. 28-35.

[22] Ullman, G. L., Dudek, C. L., and Balke, K. N. (1994), "Effect of Freeway Corridor Attributes on Motorist Diversion Responses to Travel Time Information", Transportation Research Record 1464, TRB, National Research Council, Washington, D.C., pp. 19-27.

[23] Kroes, E. P. and Sheldon, R. J. (1988), "Stated Preference Methods: An Introduction", Journal of Transport Economics and Policy, Vol. 22, pp. 11-25.

[24] Ben-Akiva, M. and Lerman, S. R. (1995), Discrete Choice Analysis: Theory and Application to Travel Demand, MIT Press, Cambridge, MA.

[25] Neter, J. Kutner, M. H., Nachtsheim, C. J., and Wasserman, W. (1996), Applied Linear Statistical Models, $4^{\text {th }}$ Edition, Irwin Press.

[26] Khattak, A. J., and Khattak A. J. (1998), "Comparative Analysis of Spatial Knowledge and En-route Diversion Behavior in Chicago and San Francisco: Implications for Advanced Traveler Information Systems", Transportation Research Record 1621, TRB, National Research Council, Washington, D.C., pp. 27-35. 
APPENDIX 


\section{A Survey of Driver Attitudes Towards the Content of Variable Message Signs}

\section{Joint Transportation Research Program}

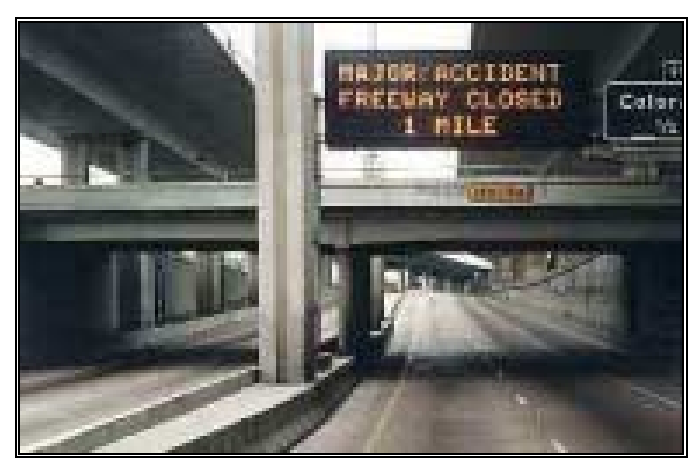

\section{Part I: About Yourself}

1. Gender:

$\square$ Male

Female

2. What is your age group?
$\square$ Less than 20 years
20-29 years
30-39 years
40-49 years
50-64 years
65 or older

3. What is the highest level of education you have completed?
$\square$ High school or less
$\square$ Some college
$\square$ College graduate
$\square$ Postgraduate

4. How many persons including yourself live in your household? persons

\section{Part II: Your Attitudes and Preferences}

The Indiana Department of Transportation is currently installing variable message signs along a sixteenmile segment of interstates 80 and 94 (I-80/94) in northwestern Indiana, better known as the Borman Expressway. We are interested in hearing your opinion about how these signs might influence your driving.

1. Are you familiar with variable message signs?

$\square$ Yes $\quad \square$ No

2. Are you a regular driver in the Borman Expressway region?

$\square$ Yes $\quad \square$ No [If answer is 'No', proceed to question number 4]

3. How familiar are you with alternate routes besides your regular route?
$\square$ Very familiar
$\square$ Familiar
$\square$ Undecided
$\square$ Not familiar
$\square$ Not familiar at all

4. What is your average work commute trip time?
5-10 minutes
10-30 minutes
30-60 minutes
More than 60 minutes
None 
5. If traffic congestion exists, a variable message sign may suggest you to take an alternate route. Would you consider diverting to the suggested alternate route if:
Adverse weather conditions are present?
It is nighttime?
$\square$ Yes
$\square$ No
It is nighttime? $\quad \square$ Yes
$\square$ No

6. Would you take a suggested alternate route if you believe that it would be longer than your current route?
$\square$ Strongly agree
$\square$ Agree
$\square$ Undecided
$\square$ Disagree
Strongly disagree

7. If you are on a work related trip, what travel time savings on the alternate route will convince you to divert?
$\square$ 5-10 minutes
10-30 minutes
$\square$ 30-60 minutes
$\square$ More than 60 minutes
$\square$ None

8. If you are on a personal trip, what travel time savings on the alternate route will convince you to divert?
$\square$ 5-10 minutes
10-30 minutes
$\square$ 30-60 minutes
More than 60 minutes
$\square$ None

9. If an accident occurs on your current route, what expected delay on the route will convince you to divert?
$\square$ 5-10 minutes
$\square$ 10-30 minutes
$\square$ 30-60 minutes
$\square$ More than 60 minutes
$\square$ None

10. Do you prefer freeway travel, if available?
$\square$ Always
$\square$ Sometimes
Does not matter
Never

11. Do you consider the neighborhood of your travel route when planning your regular commute?
$\square$ Always
$\square$ Sometimes
$\square$ Does not matter
$\square$ Never

12. When an accident occurs, a variable message sign can display information on its occurrence, location, duration, and/or detour strategies (route advisory). If an accident occurs ahead, indicate your willingness to divert to an alternate route if the variable message sign indicates:

$$
\text { High Low }
$$

\begin{tabular}{|l|l|l|l|l|l||}
\hline Location of the accident and the expected delay. & 5 & 4 & 3 & 2 & 1 \\
\hline Location of the accident and the best detour strategy. & 5 & 4 & 3 & 2 & 1 \\
\hline Occurrence of accident only. & 5 & 4 & 3 & 2 & 1 \\
\hline Expected delay and the best detour strategy. & 5 & 4 & 3 & 2 & 1 \\
\hline Location of the accident only. & 5 & 4 & 3 & 2 & 1 \\
\hline Expected delay only. & 5 & 4 & 3 & 2 & 1 \\
\hline Location of the accident, expected delay and the best detour strategy. & 5 & 4 & 3 & 2 & 1 \\
\hline The best detour strategy only. & 5 & 4 & 3 & 2 & 1 \\
\hline
\end{tabular}

13. Please provide us with any comments you may have on variable message signs and what messages might be useful for you (optional): 